\title{
Early stress, cortisol in hair and health among children in different psychosocial environments
}

\author{
Jerker Karlén
}

Division of Community Medicine/General Practice

Department of Medical and Health Sciences

Linköping University, Sweden

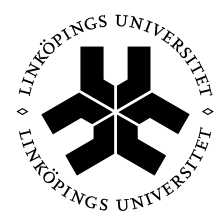

\section{Linköping University FACULTY OF HEALTH SCIENCES}

Linköping 2014 
COJerker Karlén, 2014

Cover illustration: Per Karlén, www.perpictures.com

Published papers have been reprinted with the permission of the copyright holder.

Printed in Sweden by LiU-Tryck, Linköping, Sweden, 2014

ISBN 978-91-7519-243-7

ISSN 0345-0082 
To Ida, Justus and Edith

"Reality leaves a lot to the imagination." - John Lennon

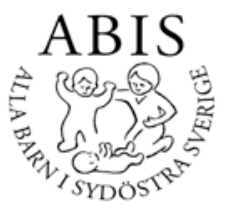





\section{CONTENTS}

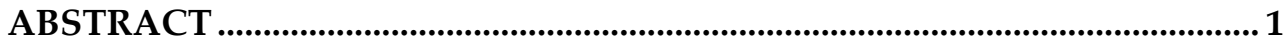

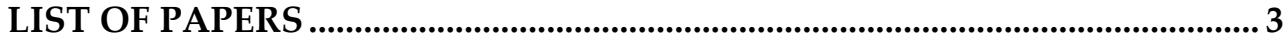

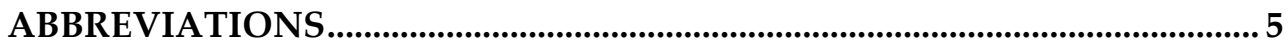

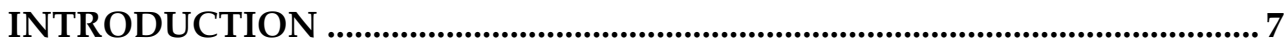

Psychosocial Stress ......................................................................................... 7

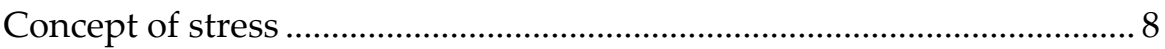

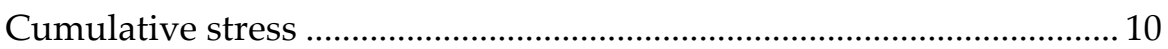

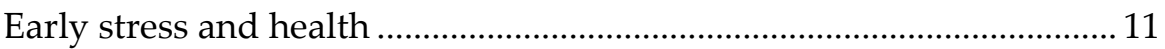

The Stress Response and HPA Axis ........................................................14

Assessing HPA axis activity ……………………….............................. 16

Child cortisol regulation .......................................................................... 17

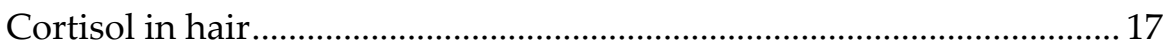

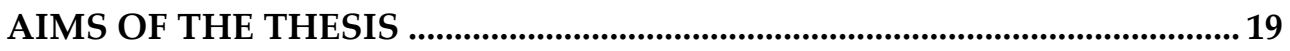

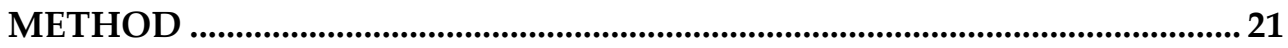

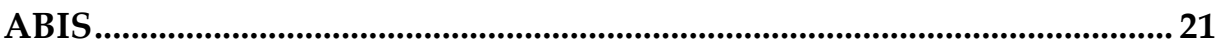

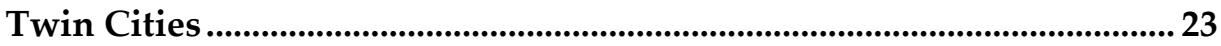

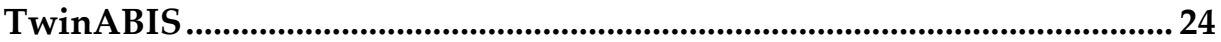

Cortisol in Hair Analysis........................................................................... 26

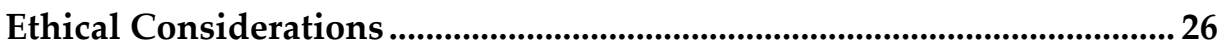

Statistical Analyses............................................................................... 27

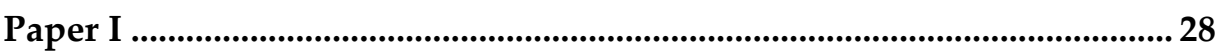

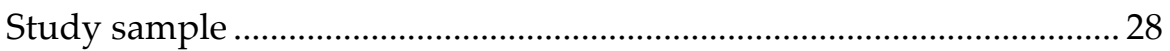

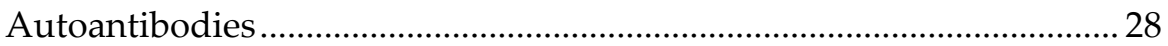

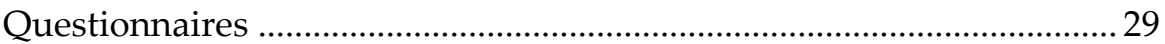

Paper II......................................................................................................... 29

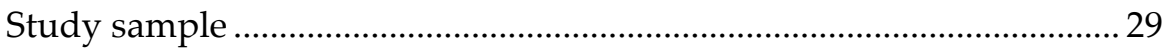

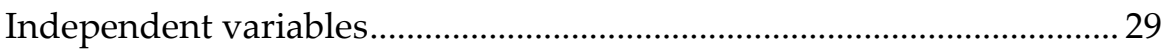

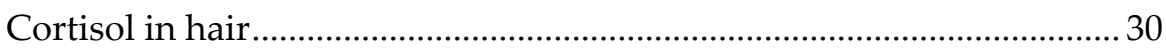

Paper III ............................................................................................................ 30

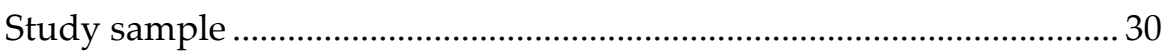

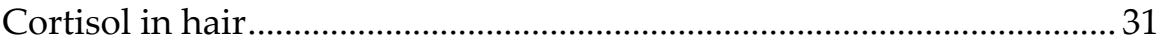




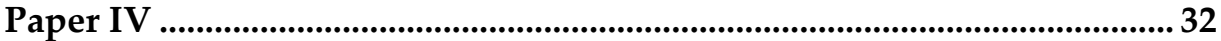

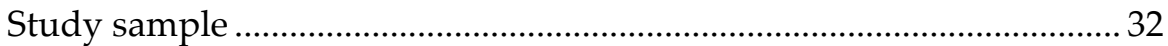

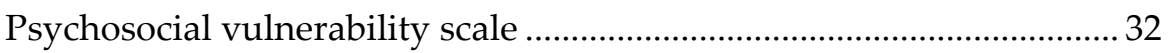

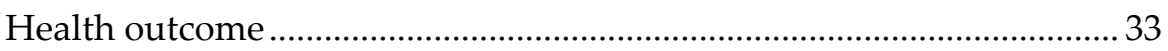

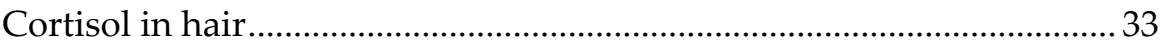

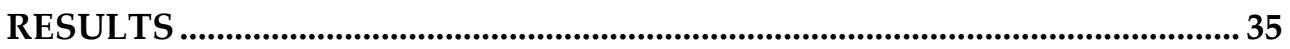

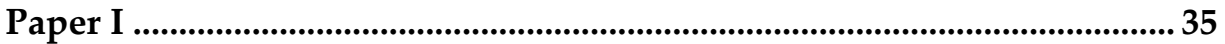

Diabetes-related autoantibodies in the twin cities..................................... 35

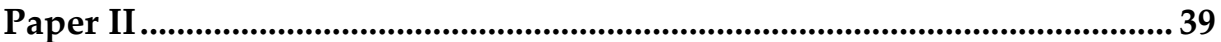

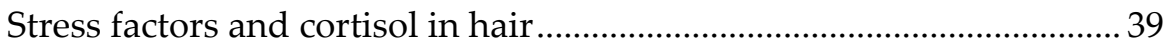

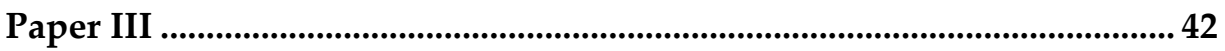

Child and mother hair cortisol................................................................ 42

Cortisol in hair socio-demographic factors .............................................. 45

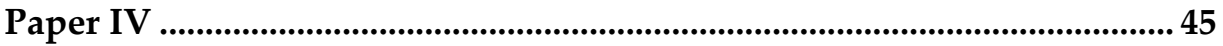

Psychosocial vulnerability and cortisol in hair ......................................... 46

Psychosocial vulnerability and health outcome....................................... 48

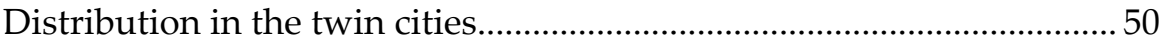

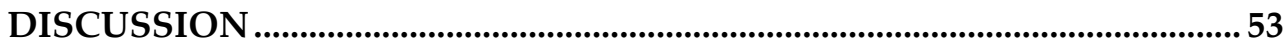

Main Findings ………......................................................................................... 53

Interpretation of Findings .............................................................................54

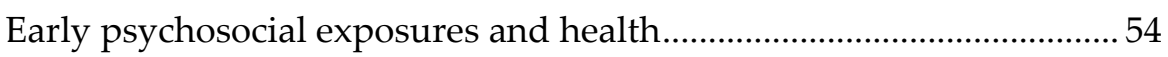

Psychosocial factors and cortisol in hair ..................................................56

Study Limitations and Methodological Considerations ...............................60 60

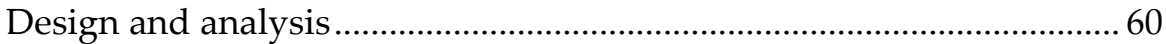

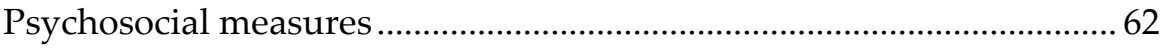

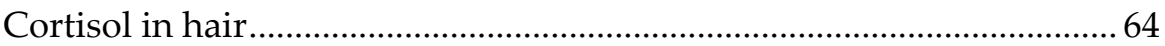

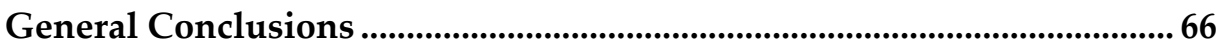

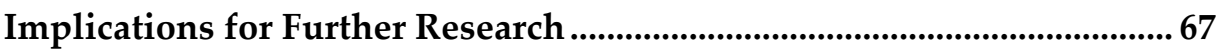

Research possible within the ABIS-study ................................................. 68

POPULÄRVETENSKAPLIG SAMMANFATTNING .........................................69

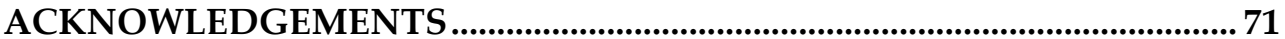

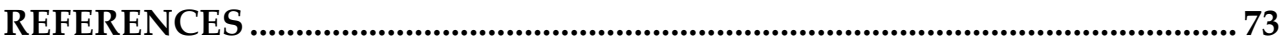




\section{ABSTRACT}

Psychosocial circumstances during early life are increasingly recognized as crucial, not only for the growing individual but also for health throughout life. A possible mechanism could be physiologic dysregulation due to stress. Cortisol in hair is a new biomarker that allows assessment of long-term activity of the hypothalamic-pituitary-adrenal axis.

The objective of this thesis was to investigate the relationship between early stress, levels of cortisol in hair and health among children in different psychosocial environments.

The ABIS-study is a prospective population-based cohort study of every child born in southeast Sweden between Oct 11997 and Oct $11999(\mathrm{~N}=21,700)$ in which approximately 17,000 families (79\%) participated. The studies presented in Papers I, III and IV were based on ABIS data on children aged 1, 3, 5 and 8 years concerning stress related psychosocial variables as well as hair samples and diabetes related autoantibodies. Papers I and IV compared a subsample $(n=2,448)$ from two different social environments. Paper III consisted of a subsample of 100 children as well as their mothers. Paper II covered 99 university students.

Paper I showed that the risk for diabetes-related autoantibodies, both against GADA and IA-2A ( $>95 \%$ cut off), was significantly higher $(\mathrm{p}<0.0001)$ among children from the blue-collar than from the white-collar city. This difference persisted still after adjustment for other previously documented risk factors. In paper II the method of measuring cortisol concentrations in hair was developed and mean cortisol levels were significantly related to serious life events $(\mathrm{p}=0.045)$ among the students. Paper III demonstrated that, in children from one to eight years of age, cortisol levels in hair decreased over time and correlated to each succeeding age, between years 1 and $3(r=0.30, p=0.002), 3$ and $5(\mathrm{r}=0.39, \mathrm{p}=0.001)$, and 5 and $8(\mathrm{r}=0.44, \mathrm{p}=0.001)$. Repeated measures gave a significant linear association over time $(\mathrm{p}=0.001)$. Maternal hair cortisol levels during the second and third trimester and child hair cortisol at year 1 and 3 
was also significantly associated. Paper IV showed that children with prenatal psychosocial exposures had higher infant cortisol levels in hair $(B=0.40$, $\mathrm{p}<0.0001$, adjusted for gender and size for gestational age) in a dose-response manner and were more often $(\mathrm{p} \leq 0.05)$ affected by 12 of the 14 most common childhood diagnoses with a general pattern of rising ORs.

In conclusion, the findings in this thesis showed that children born into an environment fraught with adverse psychosocial exposures seem to have an increased hypothalamic-pituitary-adrenal axis activity. It appears to be persistent throughout early childhood and affect health negatively, as evidenced through common childhood diseases and levels of autoantibodies. A widespread and dose response-like effect of adverse psychosocial circumstances was seen on the different outcomes studied throughout this thesis. This supports the model of physiologic dysregulation as a plausible pathway in how the duration and number of early detrimental exposures act as a trajectory to health disparities. Knowledge of these relationships could be valuable in selecting preventive measures, not least in primary care. Moreover, given the prolonged nature of exposure to a stressful social environment, the novel biomarker of cortisol in hair appears to be a useful aid in studies on how long-term stress affects health and may be particularly relevant when applied to research on children. 


\section{LIST OF PAPERS}

This thesis is based on the original publications, which are referred to in the text by their Roman numerals I-IV.

Paper I. Karlén J, Faresjö T, Ludvigsson J. Could the social environment trigger the induction of diabetes related autoantibodies in young children? Scand J Public Health 2012;40:177-82.

Paper II. Karlén J, Ludvigsson J, Frostell A, Theodorsson E, Faresjö T. Cortisol in hair measured in young adults - a biomarker of major life stressors? BMC Clin Pathol 2011;11(1):12.

Paper III. Karlén J, Frostell A, Theodorsson E, Faresjö T, Ludvigsson J. Maternal influence on child HPA axis: a prospective study of cortisol levels in hair. Pediatrics 2013;132:1333-40.

Paper IV. Karlén J, Ludvigsson J, Hedmark M, Faresjö A, Theodorsson E, Faresjö T. Impact of prenatal psychosocial exposures on hair cortisol levels and child health: cohort study. (Submitted to Pediatrics, August 2014) 


\section{ABBREVIATIONS}

ACTH adrenocorticotropic hormone

ABIS all babies in southeast Sweden

ANOVA analysis of variance

$\mathrm{CRH}$ corticotropin-releasing hormone

ELISA enzyme-linked immunosorbent assay

GADA glutamic acid decarboxylase antibodies

HPA hypothalamic-pituitary-adrenal

IA-2A tyrosine phosphatase antibodies

ICD international classification of diseases

OR odds ratio

PSS perceived stress scale

PTSD posttraumatic stress disorder

RIA radioimmunoassay

SAM sympathetic-adrenomedullary

SES socio-economic status

T1D type 1 diabetes 


\section{INTRODUCTION}

\section{Psychosocial Stress}

The evidence for stress as a cause of a range of diseases in modern industrial societies has grown stronger in recent decades. ${ }^{1,2}$ Psychosocial factors such as anxiety, social isolation, stressful life events and lack of control accumulate over life and increase the risk of many major public health diseases such as premature death, obesity, diabetes type 2, cardiovascular diseases and poor mental health. ${ }^{3-14}$ Increasing evidence is also emerging regarding other diseases, including for example, infections and autoimmune diseases. ${ }^{15-17}$

Children seem to be especially susceptible to psychosocial factors due to developmental dependence on the immediate psychosocial surroundings into which they are born. ${ }^{18}$ The impact can already be seen in childhood in terms of a wide range of ill health. ${ }^{19}$ According to the United Nations convention (1991) on the rights of the child, children have the right to 'the enjoyment of the highest attainable standard of health'. But the health of children is also important for other reasons. There is growing evidence that being born into environments fraught with adverse psychosocial circumstances also predisposes worse health later in life, thus early psychosocial stress acts as a health trajectory in to adulthood. ${ }^{12,20-22}$

The actual pathways linking psychosocial environmental exposures to health disparities are difficult to uncover, but a number of plausible pathways have been suggested. They range from adverse health behaviours such as sedentary lifestyle or exposure to environmental insults, to physiological dysregulation of neuroendocrine and immune responses. ${ }^{23-25}$ Whether stressful exposure takes the form of individual experiences or an adverse social environment, it has an impact on the biopsychosocial self, physiologically affecting the individual in the same way as when their life is in danger. Similarly, a disturbed physiological regulation may affect the child, making it vulnerable 
in the life just entered. This highlights the complexity of the highly integrated systems of stress.

Knowledge about the impact of early psychosocial stress and its physiologic entity can be useful as an aid in selecting preventive measures to support already vulnerable children and improving treatment approaches in health care. Studying the impact of early stress may therefore yield powerful tools in improving health for both children and future adults.

\section{Concept of stress}

In the twentieth century Walter Cannon introduced the term 'homeostasis' for the maintenance of physiological variables important for the survival of the organism. He believed that threats to this state of equilibrium awakens responses in the animal that he coined the fight or flight response. The body mobilizes to protect itself, e.g. blood is redirected to your muscles, the heart starts beating faster and blood pressure increases. Hans Selye, studying the pituitary-adrenocortical system developed this theory and defined the concept of 'stress' as the response of any demand placed upon the body. This concept was radical, because scientists previously believed that illnesses were caused by different pathogens. Later he introduced the term 'stressor', to disembroil the confusion caused by the term stress as the physiological response, not the actual force causing stress. ${ }^{2}$ Hereafter the stress research field can be viewed as being divided in to three heuristic traditions: the biological, the psychological and the sociological tradition.

Biologically oriented research can be seen as a continuation of the work of Cannon and Selye, with the focus on physiological responses to different kinds of stimuli. ${ }^{26}$ This is described in greater detail later on in this thesis.

The psychological tradition emphasizes the person's own perception of threat to the well-being of the self, and thus represents an individual's subjective conceptualization of stress. For example, Lazarus developed a theory of stress and coping (availability of cognitive and behavioural resources to deal with 
demands), where he believed that none was measurable as a single factor but rather is a result of interaction between the self and the environment. ${ }^{27}$.

In the social approach, focus has been on the environmental component of stress and its characteristics, thus stress is seen as a stimulus. Early on the focus was on the concept of changes in life, so-called 'Life Events', measured through the Social Readjustment Rating Scale often used to assess vulnerability. ${ }^{28}$ Another example is chronic strain, the persistent and demanding experiences of daily life. ${ }^{29,30}$ The group perspective is emphasized in social research on the macro level, e.g. a population perspective with place effects of the social environment on health. ${ }^{31-34}$ Stress is suggested to be a possible mediator in the 'upstream' influences of more proximal determinants of health such as social inequity. ${ }^{20,35}$

Stress is difficult to define. In the past 20 years stress research has developed rapidly, sub-specializing into widely different fields. This has created many different concepts of stress, which can be seen as a problem due to the inconsistent use of the term. ${ }^{36}$ However, there has also been development towards a more integrative approach to stress since these different fields inevitably influence each other. ${ }^{37}$ An example is the integration of sociology and psychology, often described with the umbrella term 'psychosocial' (Oxford English Dictionary's first brief definition: ...pertaining to the influence of social factors on an individual's mind or behaviour, and to the interrelation of behavioural and social factors) in, for example, studies of the effect of SocioEconomic Status (SES) on health that partly could be attributed to every individual's subjective level of control (Locus of control). ${ }^{38}$ Another evident example is that the tradition of neurobiology has evolved to be more integrated with various other disciplines such as psychology and sociology. ${ }^{39}$ Although research has primarily focused on stress as something negative, early on there were thoughts of a distinction between positive, healthy stress and negative stress. Examples are Selye's stress/eustress and Lazarus's harm/challenge models. ${ }^{27,40}$

Any single stress concept, be it social, psychological, physiological, environmental or genetic, is in the end a simplistic description of the complex whole that constitutes the human being. Therefore, the stress process is 
probably best understood when focusing on the whole instead of on specific parts. In this context the cumulative approach is able to take into account the tendency of adverse factors to cluster into account. ${ }^{41,42}$ Another important aspect is the ability to uncover possible interactions or potentiating effects that are difficult to discern while studying single factors by themselves. ${ }^{43-47}$

\section{Cumulative stress}

The body's response to stress and consequently its ability to retain homeostasis is necessary for the viability, adaption and ultimately survival of the organism. But when mobilizing resources to deal with extreme, repeated or constant threat without sufficient periods of recovery it is thought that the stress system actually could cause harm upon the body. ${ }^{48}$ Hence, time is an important factor when considering the harmful effect of stress on the individual.

Allostatic load, a term often used in the discussion of pathophysiological aspects of psychological stress, was coined in the 90s and further developed by McEwen. ${ }^{49}$ It refers to the cumulative burden of the physiological responses of the organism, which the organism must undertake in order to adapt, ultimately exerting 'wear and tear' on the body with a potential pathological outcome. ${ }^{50}$ In the social sciences the cumulative approach is usually applied as a summation index of dichotomized risk factors, e.g. in research concerning life course and the SES effect on health in adults as well as in children.1,19,51,52 


\section{Early stress and health}

It is accepted that psychosocial circumstances impact health in childhood, being associated with a wide range of ill health e.g. birth weight, neonatal mortality, stunted growth, injury, infections, obesity, mental health problems, asthma and immunological diseases. ${ }^{16,53-63}$ It is necessary, therefore to extend our knowledge on several aspects of children's stress and health. However, research into the effect of stress on children has lagged behind research into the effect on adults, and it is only during the last few decades that early childhood has been increasingly recognized as crucial for health throughout life. ${ }^{19,52,53,64-66}$ It is even suggested that conditions during foetal development affect health. ${ }^{67,68}$ Besides biological needs, ${ }^{69}$ the close social systems (e.g. carers and family) can indirectly exert important psychosocial influence on the young child. ${ }^{18}$ Moreover, the integrative approach of the psychosocial environment may be especially important when studying the effects of stress on children, this due to their dependence on the close social systems throughout their development. ${ }^{4}$

The actual biological pathways by which adverse psychosocial exposures lead to health disparities are very complex and difficult to define. However, as mentioned earlier, one plausible mechanism is physiologic dysregulation due to stress. ${ }^{70-73}$ Evidence suggests that early stress catalyses biological adaptations that change the way in which three highly integrated systems work, the nervous, the endocrine, and the immune systems, both individually and their interrelation. ${ }^{72,74-76}$ These are all integrated as a complex network that shares a common language of hormones, cytokines, receptors and neurotransmitters that facilitates communication across the network to maintain homeostasis. This network is thought to play a critical role in physical, cognitive, and emotional development by coordinating the body's response to stress in the environment. See figure 1.

As an example of this, the stress hypothesis concerning the induction of diabetes-related autoantibodies introduced by Johnny Ludvigsson 2006, suggests that psychological stress via cortisol and insulin resistance may induce beta-cell stress in an otherwise predisposed individual. ${ }^{77}$ This could 
trigger an autoimmune beta-cell destruction leading to Type 1 diabetes (T1D). ${ }^{16,78}$ Diabetes-related autoantibodies are markers of on-going beta-cell damage in the pancreas and appear before the onset of T1D. Higher concentrations of these autoantibodies, especially higher concentrations of more than one them, increase the risk of developing T1D and can consequently be used to identify subjects at risk of developing the disease. .9,80 $^{79}$ Another example is adverse life events or stress with a prolonged character, such as child abuse or neglect, which may lead children into risky health behaviours including smoking and alcoholism. This also appears to be associated to biological changes in the nervous system e.g. smaller cortex volume, the endocrine system, higher levels of cortisol in saliva and changes in immune functioning with elevated levels of the antibody IgA (immuneglobulin A). ${ }^{81-83}$ These changes then possibly give rise to stress-related diseases in adulthood such as cardiovascular events and depression. $8,53,84$

The use of the term early childhood is inconsistent in the literature. Most often it is referring to life from birth to about eight years, but according to international standards (WHO Commission on the Social Determinants of Health) it also includes the prenatal developmental period. ${ }^{85,86}$ In this thesis, early childhood represents the time period from birth to eight years, excluding the prenatal period. Early life as well as early stress is further used to describe both time periods. 


\section{Early Childhood Psychosocial Environment}

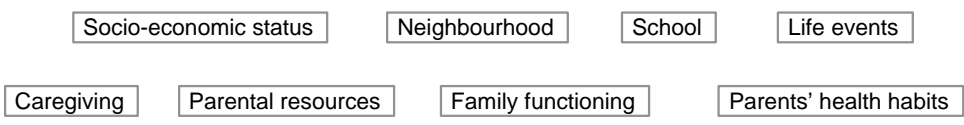
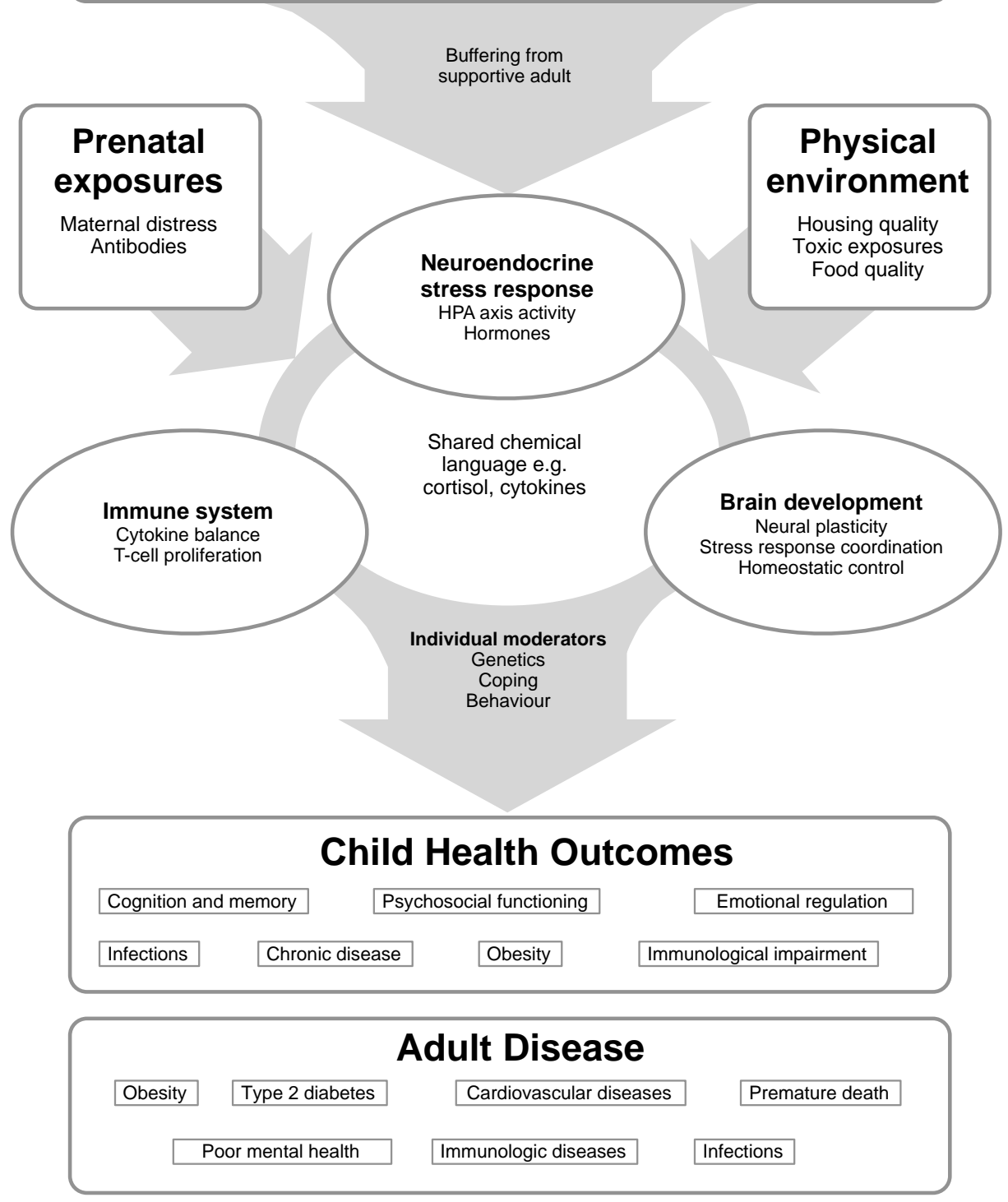

Figure 1. A model of early life experiences leading to individual health outcomes.

(Inspired by figure, M Riis ${ }^{85}$ ). 


\section{The Stress Response and HPA Axis}

The neuroendocrine hypothalamic-pituitary-adrenal (HPA) axis is a wellstudied pathway that together with the sympathetic-adrenomedullary (SAM) system is thought to be a main actor in physiological stress. Aside from these systems, other cytokines and hormones, such as angiotensin, prolactin and oxytocin, are released during the stress response. ${ }^{87}$ In short, the HPA circuits' response to strain and stressors cause negative affective states, e.g. anxiety, that alter the production of corticotropin-releasing hormone $(\mathrm{CRH})$ in the paraventricular nucleus of the hypothalamus. In response to levels of $\mathrm{CRH}$, adrenocorticotropic hormone (ACTH) is released from the pituitary gland out to the circulating blood, ultimately reaching the cortex of the adrenal gland, resulting in the synthesization of cortisol. ${ }^{88}$ Cortisol regulates its own secretion through negative feedback inhibition by binding to its receptor on cells in the hypothalamus and pituitary gland, and has the effect of inhibiting secretion of tropic hormones. See figure 2.

This stress response is thought to be a plausible physiological mechanism through which stressors influence disease risk. For example, the HPA axis could be part of the pathophysiological mechanism between childhood abuse and later depression and anxiety. ${ }^{89}$ Other examples are atrophy of parts of the brain due to chronic stress, ${ }^{35}$ as well as a significant degree of cognitive impairment. ${ }^{90}$ The latter two are examples of how interdependent these three systems are - psychosocial stress affects mental health, which leads to dysregulation of physiological systems, which in turn affects the brain and its mental ability. 


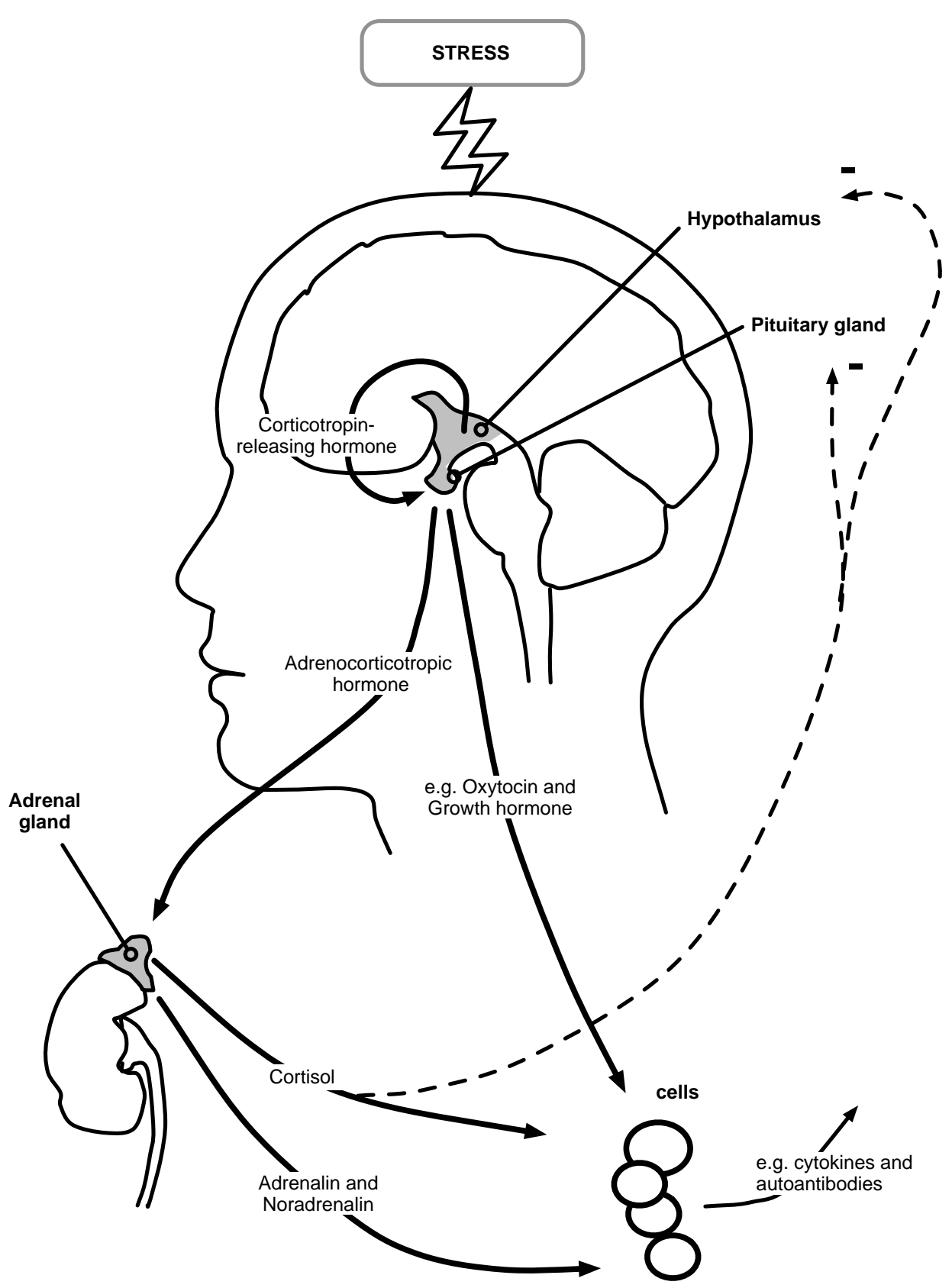

Figure 2. The stress response and function of the HPA axis. 


\section{Assessing HPA axis activity}

The most extensively used method of measuring stress response is to assess the activity of the HPA axis through levels of cortisol concentrations in saliva. ${ }^{71}$ The method has certain advantages: it is non-invasive and consequently less stressful, cheap, and can be performed by non-medical personnel in many different environments. Its technical accessibility and noninvasiveness has made it popular and it is mostly used in psychological and neuroendocrine experimental studies, especially among studies in children. Studying behavioural and hormonal reactions to potentially stressful situations is common, for example temporal separation from the mother during attachment assessments. ${ }^{91}$

Unfortunately, current methods of measuring cortisol, including concentrations in saliva, blood or urine, only cover a spot time interval and cannot detect stress longitudinally or retrospectively. Typically, several measurements of cortisol are required from each individual in order to assess a representative cortisol concentration, with levels varying greatly in each individual depending on the circadian rhythm, among other things. ${ }^{92,93}$ Sauvé et al. also demonstrated this in their 2007 study by showing that cortisol in hair correlated with 24-hour urinary cortisol but not with serum or salivary cortisol, which only measure momentary levels of cortisol. ${ }^{94}$ Also, since situational factors such as physical exercise in conjunction with sampling seem to affect cortisol levels, ${ }^{95-97}$ it is therefore reasonable that nervousness associated with sampling can affect cortisol levels in methods measuring momentary stress. 


\section{Child cortisol regulation}

Since cortisol levels are important in the diagnosis of diseases related to the HPA axis, such as Cushing's and Addison's disease, there are some older studies based on rather crude blood reference values, especially in children.98,99 A rather large study of 670 children aged 1 day to 17 years showed that median serum cortisol levels were high in the first 15 days after birth and then steadily decreased until rising again at the onset of puberty, reaching a plateau at adolescence. ${ }^{100}$ Moreover, cortisol studies in saliva indicate that the HPA axis is highly reactive and unstable at birth as well as correlating to the pubertal stage. ${ }^{101}$ Infants seem to be born without the pulsatile variation, the so-called circadian (diurnal) rhythm, where levels of cortisol are at their highest in the early morning. ${ }^{102}$ However, there are contradictory results as to when it begins. Some studies point toward the age of about one month while others see no circadian rhythm before nine months of age. ${ }^{103,104}$ Even when the circadian rhythm has started it seems to differ to that of adults, ${ }^{101}$ possibly because of variations according to sleep and feeding patterns.93 Among neonates it has been shown that hospitalized infants have higher levels of cortisol in saliva compared to controls. ${ }^{105}$. They also have higher cortisol levels as a function of the period of stay in the ventilator during neonatal intensive care. ${ }^{106}$ Some evidence suggests that prenatal stress could shape the development of the HPA axis, often measured through short-term output of the stress hormone cortisol in saliva. ${ }^{107}$

\section{Cortisol in hair}

The shortcomings of the present cortisol-measuring methods call for a better procedure in determining extended and long-term exposure to stress. Hair has been used as a substrate for measuring environmental agents, drugs or toxins for a number of years and quite recently has allowed the retrospective measurement of steroid hormones, ${ }^{108,109}$ including cortisol levels, in hair. ${ }^{110-112}$ Cortisol is assumed to be incorporated into the hair after diffusion from blood plasma circulating in the capillaries that supply the hair roots as the hair grows. ${ }^{113}$ Furthermore, since hair grows approximately 1 centimetre per 
month, it is also suggested that it could be used as a retrospective calendar of HPA activity during specific time periods preceding sample collection. ${ }^{113}$ Initial studies on primates showed that cortisol levels in their hair increased when exposed to the stress of relocation, and that the cortisol levels also increased in serum and saliva respectively. ${ }^{114,115} \mathrm{~A}$ few subsequent initial studies on humans indicate that the level of cortisol in hair may reflect the activity of the HPA axis. ${ }^{116,117}$ Furthermore, correlations could be seen between specific stressors and cortisol in hair in selected groups. For example, neonates were shown to have higher cortisol levels depending on the period of stay in neonatal intensive care. ${ }^{106}$ For a group of patients with chronic pain, higher hair cortisol levels were found compared to a control group. ${ }^{118}$ In a proof-ofconcept study by Kirshenbaum et al., cortisol levels increased in near-scalp hair segments of pregnant women, which corresponded to the well-known increase of blood cortisol levels in the third trimester of pregnancy. ${ }^{118-122}$

The last couple of years have seen a rapid emergence of research concerning concentrations of cortisol in hair. So far it seems that there is a positive association between cortisol levels in hair and different kinds of stressors, such as life events, chronic pain, unemployment, shift work and parental income. ${ }^{120-}$ 123 So far, to our knowledge, no clinical standards or reference values have been presented, so the magnitude of the physiologically plausible cortisol in hair concentrations is unknown. The individual's perception of stress or selfreported stress-related measures is not necessarily equivalent to stress measured by biomarkers, and studies focusing on stress-related measures, such as Perceived Stress Scale (PSS), Hospital Anxiety and Depression scale, Trier Inventory for the Assessment of Chronic Stress, Beck Depression Inventory, have indeed found at best diverging associations. ${ }^{123-126}$ Furthermore, research focusing on mental illness has shown very inconsistent results, with studies reporting both high and low hair cortisol levels in association with, for example, depressed and patients diagnosed Post Traumatic Stress Disorder (PTSD). ${ }^{127-129}$ A few studies on cardiovascularrelated problems have shown a relationship to obesity, diabetes type 2, level of heart failure as well as myocardial infarction. ${ }^{130-134}$ 


\section{AIMS OF THE THESIS}

The general aims of this thesis were to investigate the relationship between early stress, levels of cortisol in hair as a marker for HPA axis activity and health among children in different psychosocial environments.

The specific aim for each paper was:

Paper I. To compare the concentration of diabetes-related autoantibodies in one-year-old children from different social environments, two equally sized neighbouring but socio-economically different twin cities. This while taking other previously documented risk factors of autoimmunity into consideration.

Paper II. To investigate whether concentrations of cortisol measured in hair extracts correlate with perceived stress, serious life events and perceived health in young adults, as well as developing the method for measuring cortisol concentrations in hair.

Paper III. To explore hair cortisol concentrations prospectively in children from one to eight years of age and its possible association to the mother's cortisol levels during pregnancy. Furthermore, to investigate possible links between early stress exposures and child hair cortisol concentrations.

Paper IV. To examine whether adverse psychosocial circumstances, i.e. psychosocial vulnerability in the family during pregnancy, alter infant cortisol concentrations in hair. Furthermore, to investigate a possible relation to diagnose risk on children followed prospectively until the age of ten years. 


\section{METHOD}

\section{ABIS}

All babies in southeast Sweden (ABIS) is a population-based prospective cohort study aimed to examine the aetiology of T1D and other immune-related diseases. The parents of all $\mathrm{N} \approx 21,700$ babies in the southeast of Sweden born between 1 October 1997 to 1 October 1999 were asked to participate, figure 3. The participating families and their children have been followed prospectively with regular questionnaires and biological samples, such as hair, stool, breast milk, urine and blood samples, including cord blood. The parents of about 17,000 children (78\%) initially gave their informed consent to participate. Data were collected by the nurses at 250 well-baby clinics in conjunction with the Swedish child check-ups. The current thesis was based on data provided at birth ( 2 weeks) and age 1, 3, 5 and 8 . No reminders were used. At 8 years both the child and the parent answered a questionnaire that was sent home to the family. For an overview of the design of the ABIS-study data collection see figure 4. Follow-up rate at the age of 1 year was $67 \%$. When comparing the ABIS population to available SCB-data (Statistics Sweden, 1999) ${ }^{135}$ the sample was representative of Sweden concerning the parents' education. The proportion of parents born abroad in the study cohort was similar to the proportion of individuals born abroad in the region, and only slightly smaller than the proportion in Sweden as a total. Furthermore, the sample was representative of Sweden regarding the parents' education. There were no difference between the original ABIS-cohort or the follow-up samples concerning: foreign origin, education, and parental age. ${ }^{136}$ 

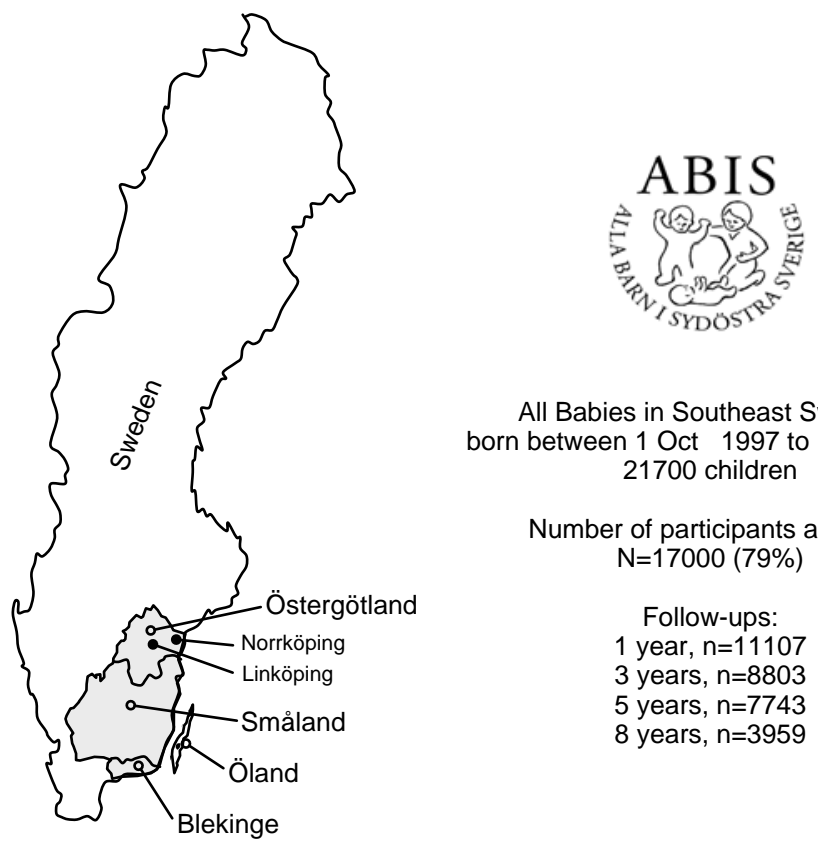

All Babies in Southeast Sweden, born between 1 Oct 1997 to 1 Oct 1999: 21700 children

Number of participants at birth: $\mathrm{N}=17000(79 \%)$

Follow-ups:

1 year, $n=11107$

3 years, $n=8803$

5 years, $n=7743$

8 years, $n=3959$

Figure 3. Map of southeast Sweden, showing the regions from where the sample for ABIS was drawn, including number of participants at the different follow-ups.

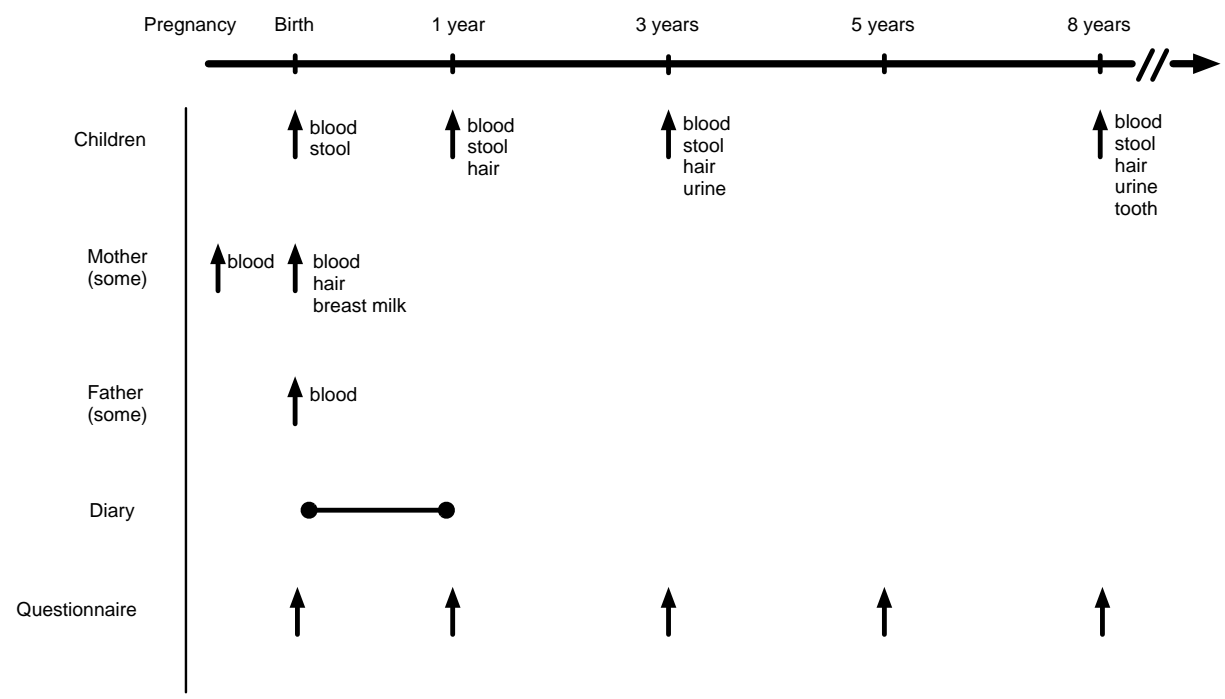

Figure 4. Design of the ABIS-study including data collection. 


\section{Twin Cities}

In this thesis, one of the underlying objectives was to focus on the stress and health of children in different social environments. On a structural community level the two Swedish cities Linköping and Norrköping in the county of Östergötland, are referred to as twin cities but they represent two different social environments. The cities are about equal in size, around 150,000 and 135,000 respectively, and geographically located within a distance of 40 kilometres. Today they could be considered as quite similar and comparable cities, but their social histories are very different as well as their present day public health. ${ }^{137}$

Norrköping is referred to as a blue-collar city. It was industrialized as early as the seventeenth century and during the industrial revolution 200 years later became a centre for the textile industry, employing many women, whose work was low paid and monotonous. The city of Linköping is referred to as a whitecollar city. It was historically centred on commerce, the Church, administration, and later also on higher education. Industrialization of Linköping started much later, in the early twentieth century, and mainly employed men within the metal industry. However, both cities underwent major structural changes from an industrial to an information society in the 1960-70s. In particular the blue-collar city was hard hit in the 1960s and 70s with factory shutdowns and mass lay-offs. The white-collar city managed this change better than the blue-collar one, most likely due to its tradition of, for example, administration and education to fall back on. These marked differences have been somewhat reduced during recent decades, but the cities may well be viewed as typical 'white-collar' and 'blue-collar' communities. Although the two cities are much alike today, there are some distinct differences in the populations. ${ }^{138}$ The inhabitants of the blue-collar city have in general a lower education, are more often smokers, exercise less, are more overweight, have shorter life expectancy, and higher frequencies of cardiovascular disease, gastrointestinal disorders, but also mental illness, musculoskeletal diseases, and rheumatism etc. ${ }^{139,140}$ These differences seems to have remained stable over the years. ${ }^{137}$ 


\section{TwinABIS}

In papers I and IV a subsample of the major ABIS-study was used. This socalled 'TwinABIS' constitutes a total of $n=2448$ children (from the city of Linköping $n=1288$ children, and from Norrköping $n=1160$ children). These cities were chosen because they represent two different social environments and because they are part of the same county council that is responsible for practically all health care with the same clinical practice guidelines. Furthermore, it is possible to study diagnoses of and health-care utilization by all the inhabitants in both primary care and hospital care in this county council, since an extensive regional Health Care Register is available

This subsample consists of every participating ABIS-child living in the urban parts of the neighbouring cities of Linköping and Norrköping. Thus it was based on the perception that there is a difference between the psychosocial environments of children living in the two cities. This difference is presumably not evident in the rural and countryside of the two communities. The number of omitted children due to this exclusion of children living in the rural parts of the two cities was $n=129(9 \%)$ in Linköping and n=20 (2\%) in Norrköping. For an overview of the samples used in Papers I, III and IV (note, Paper III included data from the whole ABIS), see figure 5. For detailed information on each of these papers see headings below. 


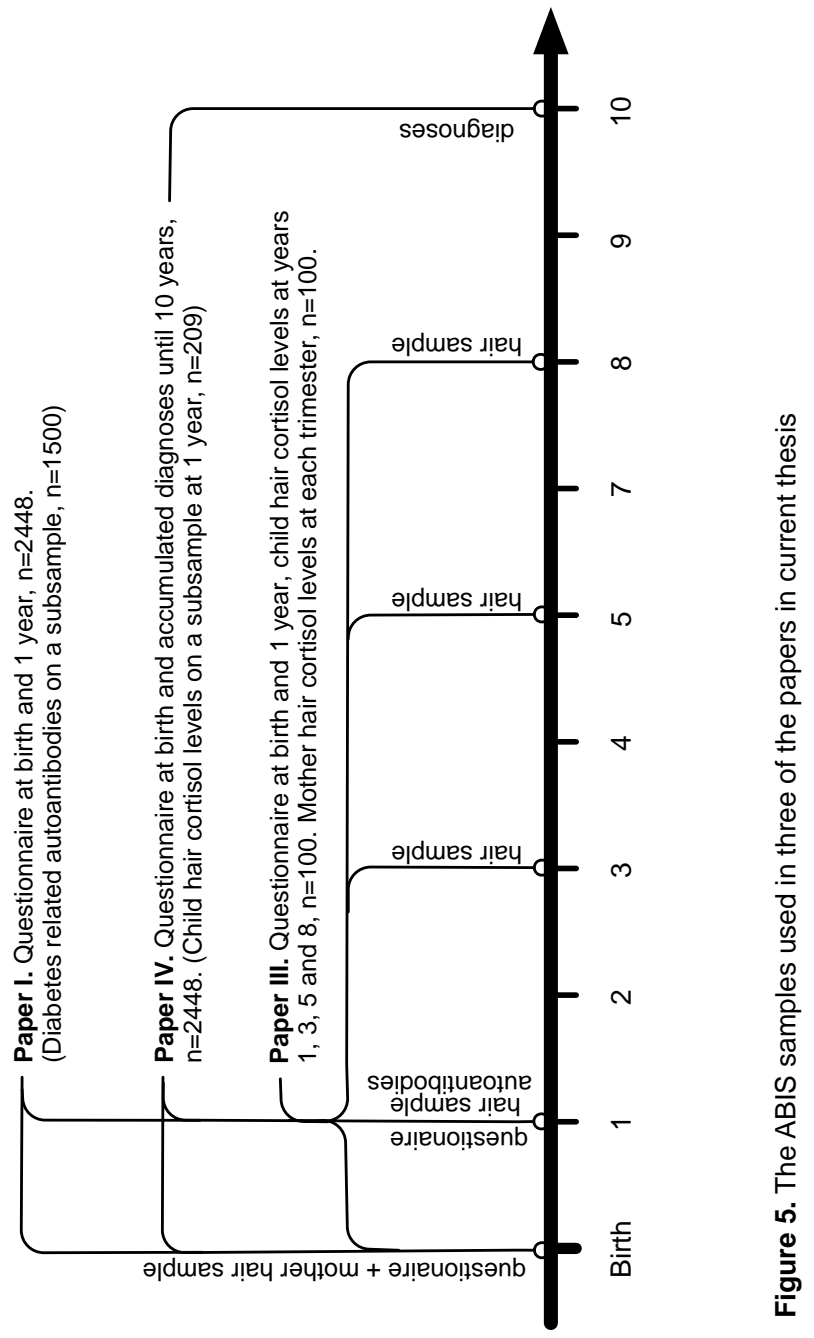




\section{Cortisol in Hair Analysis}

Cortisol concentrations were expressed as $\mathrm{pg} / \mathrm{mg}$ with a method developed inhouse using a competitive radioimmunoassay (RIA) in methanol extracts of pulverised hair. An approximately $3 \mathrm{~mm}$-thick hair and $3 \mathrm{~cm}$-long sample was cut close to the scalp from the posterior vertex area of the head. The samples were minced and extracted in methanol as explained below. Hair samples were weighed on a Sartorius MC 210p microscale, in $2 \mathrm{~mL}$ QiaGen RB sample tubes. To each tube a $5 \mathrm{~mm}$ steel ball was added and batches of five tubes were put in each solid aluminium holder. The holders, including the samples and steel balls in the sample tubes, were frozen in liquid nitrogen for 2 minutes and rapidly minced in Retch TissueLyser II at $30 \mathrm{~Hz}$ for 2 min producing very fine hair powder. One $\mathrm{mL}$ pure methanol (Chromasolv, Sigma-Aldrich) was added to each tube and each tube fixed in a metal holder on an oblique (5 degrees from the horizontal) plate on a horizontal shaker (Edmund Bühler, type B1) at room temperature, making sure that the steel balls continuously moved back and forth for ten hours. The tubes were then centrifuged and 700 $\mu \mathrm{L}$ of the supernatant moved to another sample tube for lyophilization in SpeedVac Plus SC210A (Savant) using Edwards XDS 5 vacuum pump. The extracted hair samples were then measured for concentration of cortisol. First they were dissolved in $150 \mu \mathrm{L} 0.1 \mathrm{~mol} / \mathrm{L}$ phosphate buffer, $\mathrm{pH} 7.4$ containing $0.02 \%$ bovine serum albumin (BSA) and $0.01 \%$ triton $\mathrm{X}-100$, and concentrations of cortisol measured were analysed as described by Morelius et al. ${ }^{141}$

\section{Ethical Considerations}

Papers I, III and IV are based on data from the ABIS-study. At start-up, before the child was born, parents received oral and written information as well as being offered the opportunity to watch a video about the ABIS-study. The return of a completed questionnaire as well as biological samples was considered as an informed consent. At the time of the first questionnaire (when the child was just born) the parents also had the opportunity to give their informed consent for possible upcoming linkage in the future of data 
from medical records and health-care registers. ABIS has been approved by the research ethics committee of the Faculty of Health Sciences at Linköping University, Sweden, at several times in conjunction with different sub-projects and at the Medical Faculty at Lund University, Sweden. Ethical considerations in the ABIS-project have thereafter been specifically studied in a dissertation from the university of Linköping. ${ }^{142}$ Data are stored without personal identification numbers and analyses are with due confidentiality. This thesis has a separate approval (2008-02-14, registration number M154-07) from the Regional Ethical Review Board at the Faculty of Health Sciences, Linköping University, Sweden.

\section{Statistical Analyses}

Data from questionnaires at the different follow-ups were optically scanned and manually checked for errors. Univariate analyses were executed as shown below. Multivariate regression analysis was used to control for other known associated factors and in Papers I and IV to estimate the ORs (95\% CI). Independent variables found to be significant at the $5 \%$ level in the univariate analyses were included in the final multivariate analyses. For association of continued variables, Pearson's correlation coefficient was applied (Papers II, III, IV). Outliers in the measured cortisol concentrations were identified with Grubbs test and no statistics were calculated on mean values based on small groups (i.e. groups with fewer than ten individuals). Statistical analyses were made using the Statistical Package for the Social Sciences v. 16.0 to 20.0 software in the different papers (SPSS, Chicago, IL, USA).

In Paper I univariate analyses between exposed and non-exposed groups and differences in occurrence of glutamic acid decarboxylase ( $n=65$; cut off 95th percentile positive reaction) were measured by $\chi 2$ and, in the case of a few observations under 5), Fisher's exact test was used.

In Papers II and III analysis of variance (ANOVA) was used for univariate tests. Paper II concerned adults' levels of cortisol in hair with supposedly less biological variation than the children, and thus cortisol in hair values were not logarithmized prior to analyses and outliers were ruled out due to the possible 
inclusion of measurement errors. Nevertheless, although data were not normally distributed, ANOVA was still subsequently used in all univariate analyses in paper II, including the variable Serious Life Events. This was done after consultation with two independent experienced statisticians who both recommended this method. According to them, this method is quite robust and it is even harder to get a statistically significant result with ANOVA than it is using non-parametric tests. ${ }^{143}$ Also note that Serious Life Events is still statistically significant in the multivariate analysis.

In Papers III and IV the measured cortisol concentrations were logtransformed to a normal distribution before computing inferential statistics, since their distributions were skewed. Thereafter the geometric means were presented. Paper IV used a composite vulnerability scale to compare mean numbers of items against having a diagnosis or not, as well as being transformed in to a categorical variable when testing against binary diagnosis; in both cases independent samples t-test was used.

\section{Paper I}

\section{Study sample}

The TwinABIS sample in this study yielded $n=1288$ children from the whitecollar twin city, and $\mathrm{n}=1160$ children from the blue-collar twin city. Out of these children, 709 and 788 children, respectively, were tested for tyrosine phosphatase (IA-2A) and $n=701$ and $n=708$ children were tested for glutamic acid decarboxylase antibodies (GADA).

\section{Autoantibodies}

Autoantibody analyses were done in whole blood samples from randomly selected one-year-old children in the total ABIS cohort. $n=5765$ children were tested for autoantibodies to GADA and $n=5635$ children were tested for autoantibodies to IA-2A. The autoantibody assay has been described else- 
where and validated in the Diabetes Autoantibody Standardization Program 2002 workshop with documented good sensitivity and specificity (specificity was $100 \%$ for IA-2A and $96 \%$ for GADA assays and the sensitivity was $54 \%$ and $81 \%$, respectively). ${ }^{144,145}$ In this report the cut-offs analysed were $95 \%$.

\section{Questionnaires}

Data from questionnaires in the ABIS-study were also included in this report. The mother answered one questionnaire around two weeks after child delivery; she also answered yet another when the child was one year old. Both questionnaires concerned a large set of factors that could have a possible association to the development of T1D, such as family characteristics, dietary habits, lifestyle and psychosocial factors. Questions included in this analysis were explanatory factors documented as risk factors for increased GADA and IA-2A in earlier studies and factors concerning differences in socio-economic structure between the two cities.

\section{Paper II}

\section{Study sample}

Medical and nursing students in their second semester at the Faculty of Health Sciences at Linköping University were invited to voluntarily cut hair samples and to anonymously fill in a questionnaire. $\mathrm{N}=99$ students decided to participate in the study. No exclusion criteria were applied, except for those students with crew cut or shaved hair, for which hair sampling was impossible.

\section{Independent variables}

The questionnaire covered the experience of: 1) serious life events during the last three months; this was assessed with the dichotomous (yes/no) question 
during the last three months, have you experienced something that you would describe as a serious life event? (e.g. death of a close relative, serious illness or divorce.', with a 'yes' option to describe which kind of event; 2) perceived health during the last three months, assessed by a visual analogue scale coded as 010 (ranging from 'very poor' to 'excellent'); and 3) perceived stress during the last three months, assessed with the PSS which is a 14-item instrument assessed on 5-point Likert-scales (ranging from 'never' to 'very often'). ${ }^{146}$ The association between total PSS-score, as well as each PSS-item, and cortisol concentrations was statistically tested. Background factors were measured, including sex, age, and possible confounding factors, such as coloured/permed hair and regular use of prescribed pharmaceuticals the last three months.

\section{Cortisol in hair}

Hair samples with a length of $3 \mathrm{~cm}$, cut closest to the scalp from the posterior vertex area of the head were analysed. Samples weighing $5 \mathrm{mg}$ or more were needed for maintaining a total inter-assay coefficient of variation below $8 \%$ for hair extraction and measurement of cortisol by the radioimmunoassay. The intra-assay coefficient of variation for the radioimmunoassay itself was $7 \%$ at $10 \mathrm{nmol} / \mathrm{L}$.

\section{Paper III}

\section{Study sample}

The extensive ABIS biobank was scrutinized and the first 100 children with enough hair stored to be able to measure cortisol in hair at the ages of 1, 3, 5 and 8 years of age as well as hair collected by their mothers at least covering the third trimester of the pregnancy were included. 


\section{Cortisol in hair}

Hair strands for both children and their mothers were cut closely to the scalp from the top and back of the head and then deep-frozen. A minimum of $3 \mathrm{~cm}$ hair was cut reflecting exposures during the last three months. Samples of the mother's hair were cut after child delivery. If available, at least $9 \mathrm{~cm}$ hair was cut reflecting the 9 months period of pregnancy. These were thereafter cut into $3 \mathrm{~cm}$ pieces reflecting the pregnancy trimesters. The children's hair was cut in connection to the prospective data collection at the well-baby clinics at the age of 1 year, 3 years, 5 years and 8 years.

The lowest detectable concentration was $1 \mathrm{nmol} / \mathrm{L}$ and the within- and between assay coefficients of variation were $6.1 \%$ and $9.3 \%$, respectively, at 10 $\mathrm{nmol} / \mathrm{L}$. Each of the multiple steps in the weighing, extraction and measurement contributes to the overall uncertainty, with sample mass as one of the important variables. Ten replicates of hair samples weighing 1, 2, 3, 4 and 5 $\mathrm{mg}$ were extracted and measured by the procedure described above and the coefficient of variation calculated, see table 1 below. At least $5 \mathrm{mg}$ of hair samples was subsequently used in the analysis.

Table 1. Coefficient of variation on cortisol concentrations in hair in relation to sample mass

\begin{tabular}{cc}
\hline Hair sample & Coefficient of variation \\
\hline $1 \mathrm{mg}$ & $46.2 \%$ \\
$2 \mathrm{mg}$ & $16.1 \%$ \\
$3 \mathrm{mg}$ & $12.4 \%$ \\
$4 \mathrm{mg}$ & $13.6 \%$ \\
$5 \mathrm{mg}$ & $7.9 \%$ \\
\hline
\end{tabular}




\section{Paper IV}

\section{Study sample}

A subsample of $n=2447$ children, (TwinABIS) consisting of every participant living in the urban areas of the two cities of Linköping and Norrköping was chosen. In all, $\mathrm{n}=571$ children were excluded due to incomplete data on the independent variable. The sample in this paper for subsequent analyses concerning vulnerability and International Classification of Diseases (ICD-10) diagnoses thus was $\mathrm{n}=1876$ children ( $\mathrm{n}=926$ girls and $\mathrm{n}=950$ boys). Concentration of cortisol in hair was analysed for a subsample of $n=209$ children ( $\mathrm{n}=103$ boys and $\mathrm{n}=106$ girls) with sufficient hair samples collected at age one. This sample was stratified according to the distribution of the vulnerability scale and gave an oversampled $3+$ category $(n=90)$.

\section{Psychosocial vulnerability scale}

The mothers answered a questionnaire shortly after birth containing psychosocial factors or markers in areas such as socio-economic situation, social support, empowerment, living situation and sense of coherence. A 'deficit accumulation approach' employed in earlier studies was used to create a psychosocial vulnerability scale. ${ }^{46}$ Variables in the existing database associated with detrimental impact on health as suggested in previous research were included. Some detailed answers were dichotomized to pinpoint the most vulnerable, e.g. schooling was simplified into having an education above elementary school or not (see below).

Eleven psychosocial items resulted in the final composite independent variable: the psychosocial vulnerability scale. They were: father's highest level of education elementary school; mother's highest level of education elementary school; father unemployed or on sick leave the year before pregnancy; mother unemployed or on sick leave during pregnancy; living in an apartment, as opposed to an own house; single mother; parents born abroad; maternal serious life event during pregnancy ('Have you been exposed to something which you perceive as a serious life 
event during your pregnancy?'); maternal lack of support ('Do you feel your surroundings give you the support you and your newborn child need?'); mother not feeling safe ('Do you feel safe and in the circumstances needed to give you and your newborn child a good start?'); mother worried over the possibility of child falling ill with serious disease ('How do you usually feel when you consider the possibility that your child could fall ill with a chronic or serious disease in the future?') For these, a stepwise 6-grade scale was applied, between not worried and very worried, with $4-6$ being classified as worried.

\section{Health outcome}

ICD-diagnoses (International Classification of Diseases -10) were derived from the regional Health Care Register data of all health-care visits in primary as well as in hospital care within the public financed health care, which represent practically all health care in the region. Diagnoses from birth to February 2008 were obtained, and recorded on a one-per-case basis. Children were aged eight to ten at follow-up, hence describing the cumulative incidence from birth. This follow-up was almost $100 \%$, since the dropout due to death or moving out the region was negligible. Closely related diagnoses were in some instances merged, e.g. codes J00 through to J06 were all registered in the category 'J00-J06: acute upper respiratory infections'. Categories $Q, R$ and Z were omitted. There is no evidence of systematic misclassification in this health-care register. ${ }^{143}$

\section{Cortisol in hair}

Nurses at the well-baby clinics cut the children's hair from the posterior vertex area of the head at age one and the first $3 \mathrm{~cm}$ of outgrowth was analysed for cortisol concentrations using a competitive RIA in methanol extracts, as described earlier. Hair samples between 3-10 mg were required to maintain a total inter-assay coefficient of variation below $8 \%$ for hair extraction and measurement of cortisol by the radioimmunoassay. The intra-assay coefficient of variation for the radioimmunoassay itself was $7 \%$ at $10 \mathrm{nmol} / \mathrm{L}$. 


\section{RESULTS}

\section{Paper I}

\section{Diabetes-related autoantibodies in the twin cities}

The presence of the autoantibodies IA-2A and GADA (95\% cut-off) among children aged one year in the two cities is presented in figure 6 . The number of children with autoantibodies, IA-2A as well as GADA, were significantly higher $(\mathrm{p}<0.0001)$ among children from the blue-collar twin city $(8.9 \%$ and $7.1 \%)$ than among children from the white-collar twin city (1.0 and 1.3\%). Children with both IA-2A and GADA autoantibodies were only found among the children from the blue-collar twin city ( $1.3 \%$ or $n=10$ children). This difference persisted still after adjustment for other previously documented risk factors. Since Paper 1 was published these results have been replicated at the age of three years, though notably with less differences between the twin cities. See figure 7 .

Different factors with a possible association to GADA and IA-2A positivity (95\% cut-off) are shown in table 2 and table 3 respectively. Some previously known factors were significantly associated to the autoantibody positivity in the univariate analysis. These factors remained independently and significantly associated in the multivariate analysis as well as the twin cities factor, that is, living in the blue-collar twin city compared to the white-collar city. 

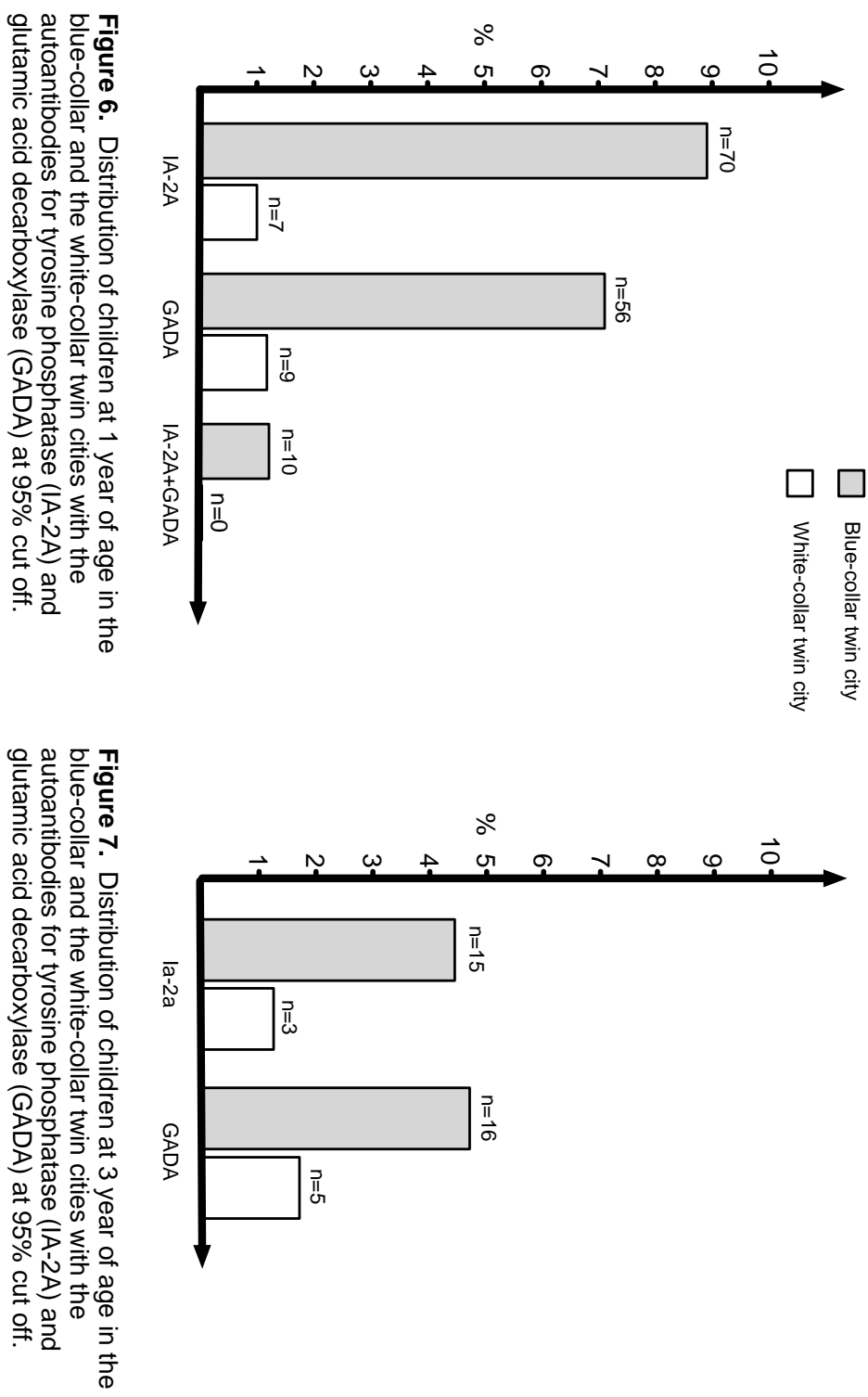


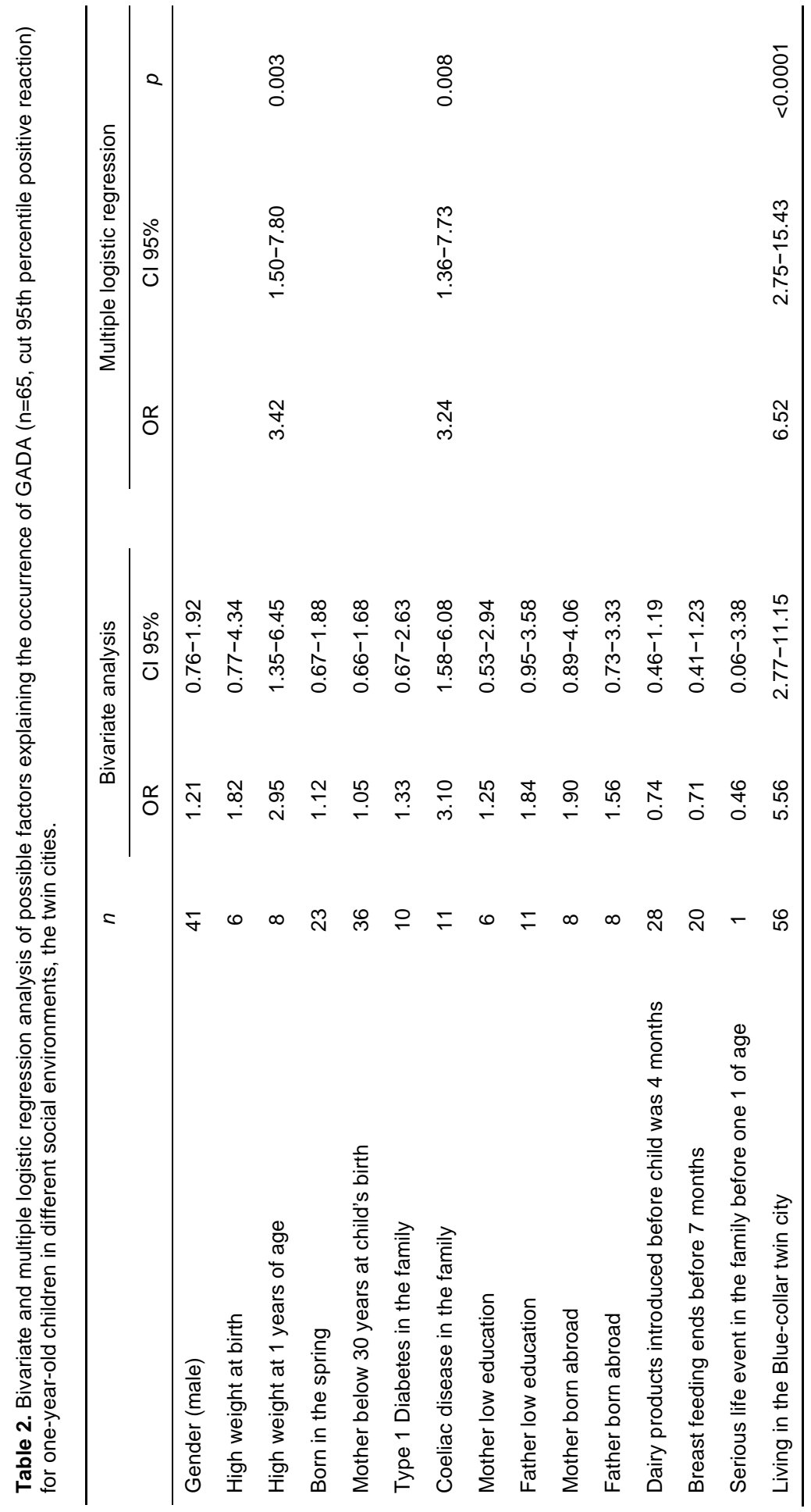




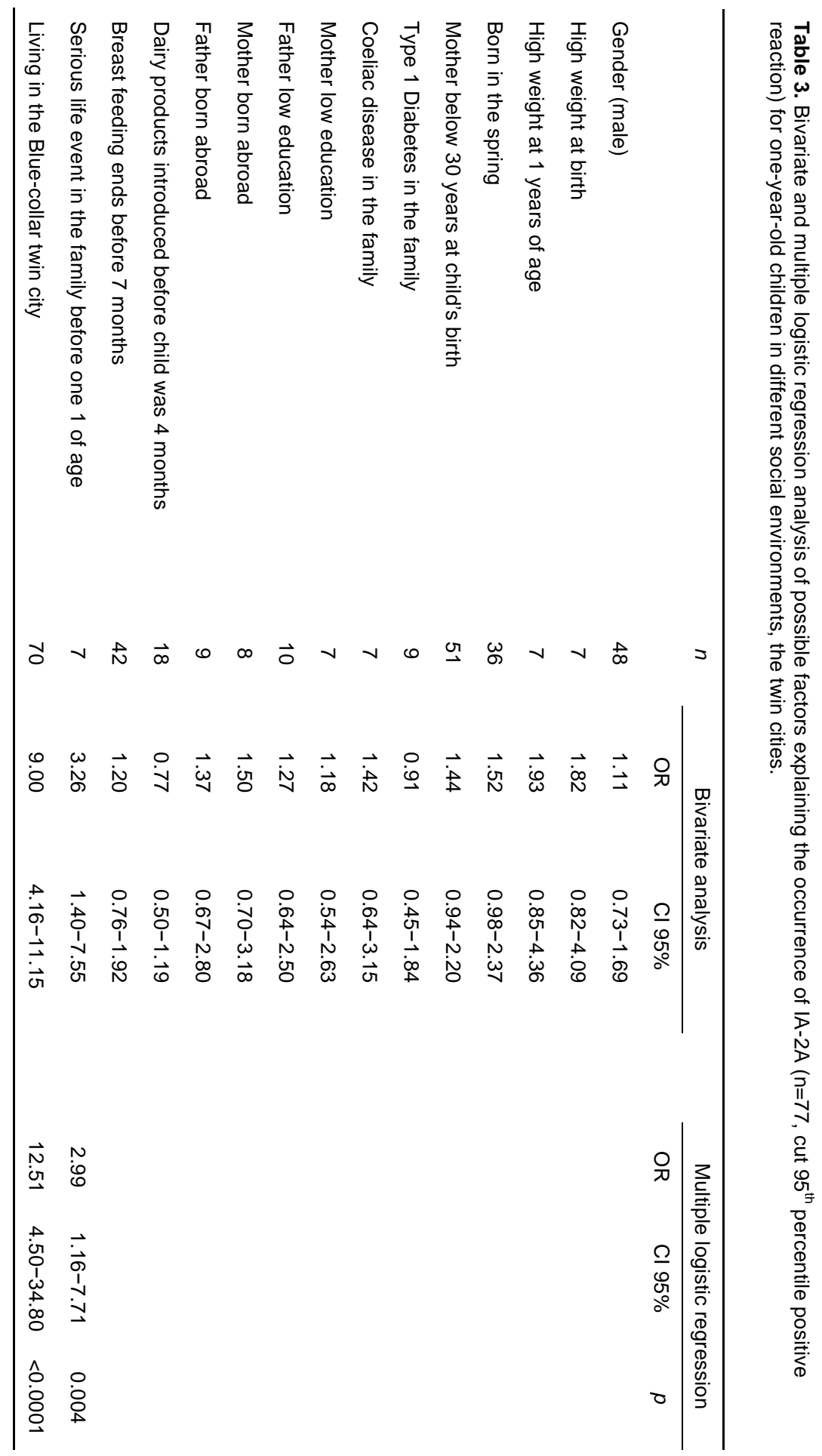




\section{Paper II}

\section{Stress factors and cortisol in hair}

Mean cortisol levels for the studied young adults were $19.93 \mathrm{pg} / \mathrm{mg}$ (s.d. 33.35), ranging from 1.45 to $212.03 \mathrm{pg} / \mathrm{mg}$. For males, the mean cortisol levels were 17.76 (s.d. 13.34) and for females 20.55 (s.d. 37.66), no difference between sexes in this respect $(p=0.726)$. Increased cortisol levels in hair were found among participants reporting that they, during the last three months, had experienced serious life events $(p=0.045)$. Also, participants reporting lower levels in the 14-item PSS had significantly higher levels of cortisol in their hair $(\mathrm{p}=0.025, \mathrm{r}=-0.061)$ as seen in table 4 . Cortisol levels were neither affected by coloured/permed hair, intake of prescribed pharmaceuticals nor self-reported health. Furthermore, in a follow-up question concerning pharmaceuticals - 'If Yes, which kind?' - no one reported the use of oral corticosteroids or other hormonal drugs of probable influence to cortisol levels. In a multiple regression model, indicators of perceived stress, perceived health and experience of serious life events were included. Only the indicator of experiences of serious life events in the last three months exhibited an independent and significant $(p=0.042)$ explanation of increased levels of cortisol in hair. Four respondents had cortisol concentrations that were considerably higher than the average (692/750/1090 and 2027 pg/mg), and were considered as outliers. Despite the anonymous data collection, two of these four outliers could be reached by open announcement. Both of them reported serious psychological problems, anorexia nervosa and severe generalized anxiety disorder with panic attacks, respectively. 


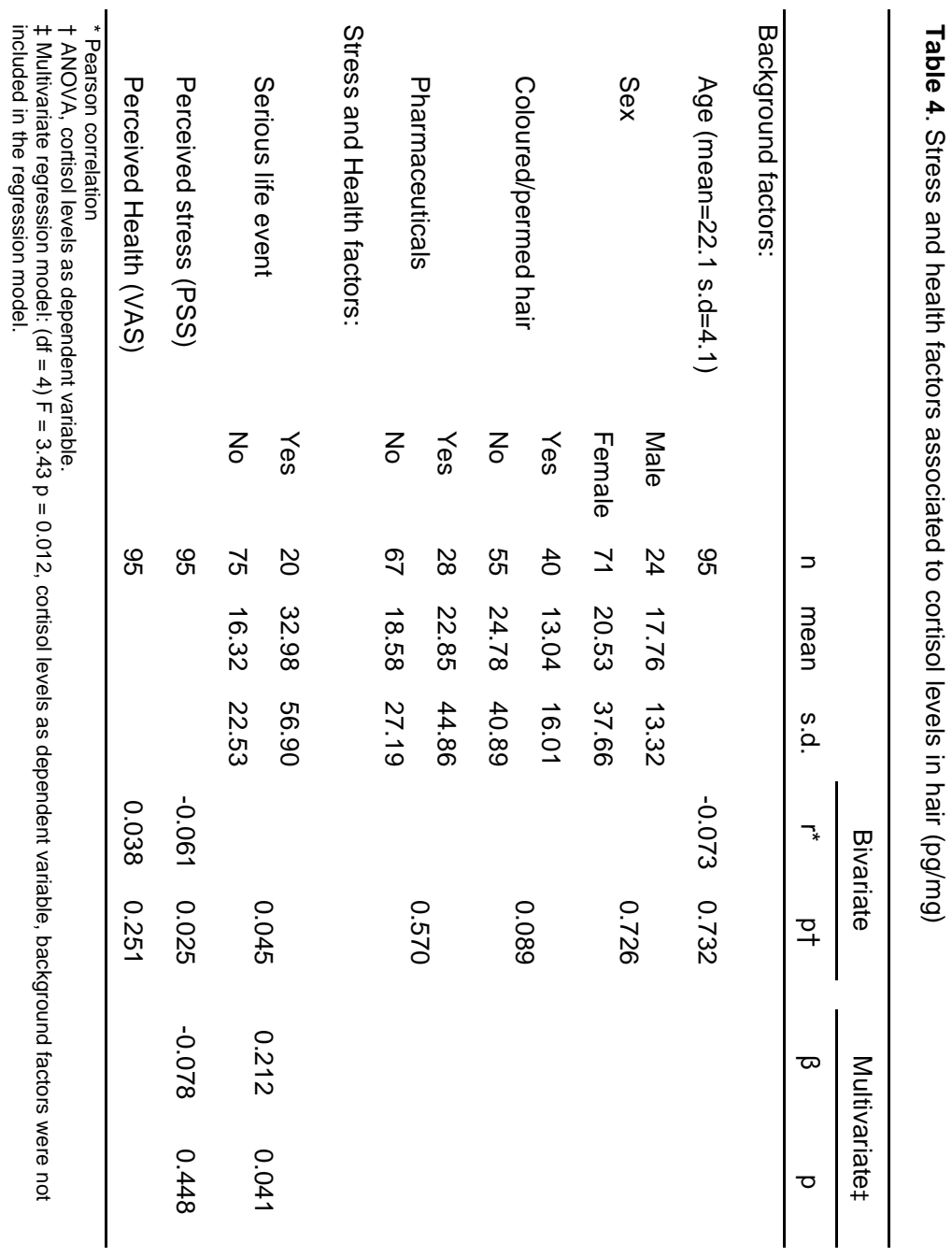


One single PSS item ('In the last three months, how often have you felt difficulties were piling up so high that you could not overcome them?') had a tendency towards exposure-response relationship, with increasing mean cortisol levels corresponding to higher levels of coping problems (Never=4.02, Almost never $=9.75$, Sometimes $=14.79$, Fairly often $=21.86$, Very often $=32.91 \mathrm{pg} / \mathrm{mg}$ respectively), although confidence intervals overlapped between all but Never and Sometimes/Fairly often, see figure 8.

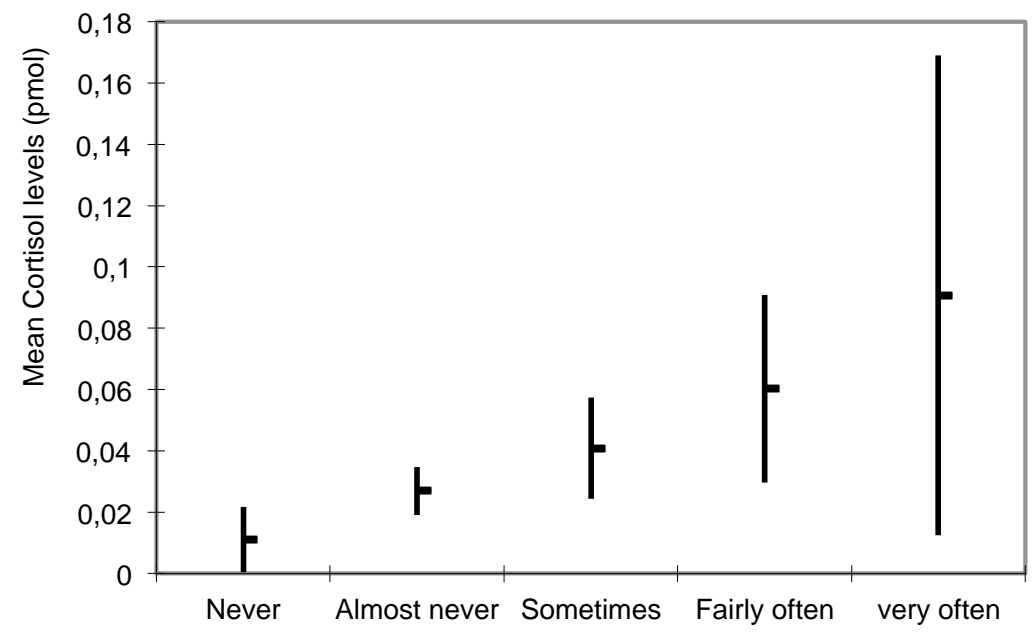

Figure 8. Mean cortisol levels $(\mathrm{Cl}=95 \%)$ and answers to the single PSS question 'In the last 3 months, how often have you felt difficulties were piling up so high that you could not overcome them?' $(\mathrm{N}=99)$. 


\section{Paper III}

\section{Child and mother hair cortisol}

The prospective, non-logarithmized hair cortisol concentrations for the children at 1,3,5, and 8 years of age are shown in figure 9. At 1 year of age they ranged from 0.18 to $1667 \mathrm{pg} / \mathrm{mg}$, at 3 from 0.87 to 983 , at 5 from 0.36 to 1299 , and at 8 from 0.34 to 402 . Cortisol values for the children decreased over time, indicated by the geometric mean values, and they were significantly positively correlated between 1 and 3 years of age and between 3, 5, and 8 years. Repeated-measures ANOVAs were also used, and a significant linear association over time was observed (epsilon=0.807, $\mathrm{p}=0.001$ ). During pregnancy, the pregnant mother's cortisol concentrations increased over time and ranged during the first trimester from 0.62 to $50 \mathrm{pg} / \mathrm{mg}$, during the second trimester from 0.33 to $263 \mathrm{pg} / \mathrm{mg}$, and during the third trimester from 0.42 to $206 \mathrm{pg} / \mathrm{mg}$. All trimesters were strongly correlated: first and second ( $\mathrm{r}=0.93$, $\mathrm{p}=0.001)$, second and third $(\mathrm{r}=0.78, \mathrm{p}=0.001)$, and first and third $(\mathrm{r}=0.74$, $\mathrm{p}=0.001)$. Maternal hair cortisol levels during the second $(n=73)$ and third trimester $(n=100)$ correlated to child levels at years 1 and 3 , whereas the first trimester $(n=40)$ did not show significant correlations, see table 5 . 


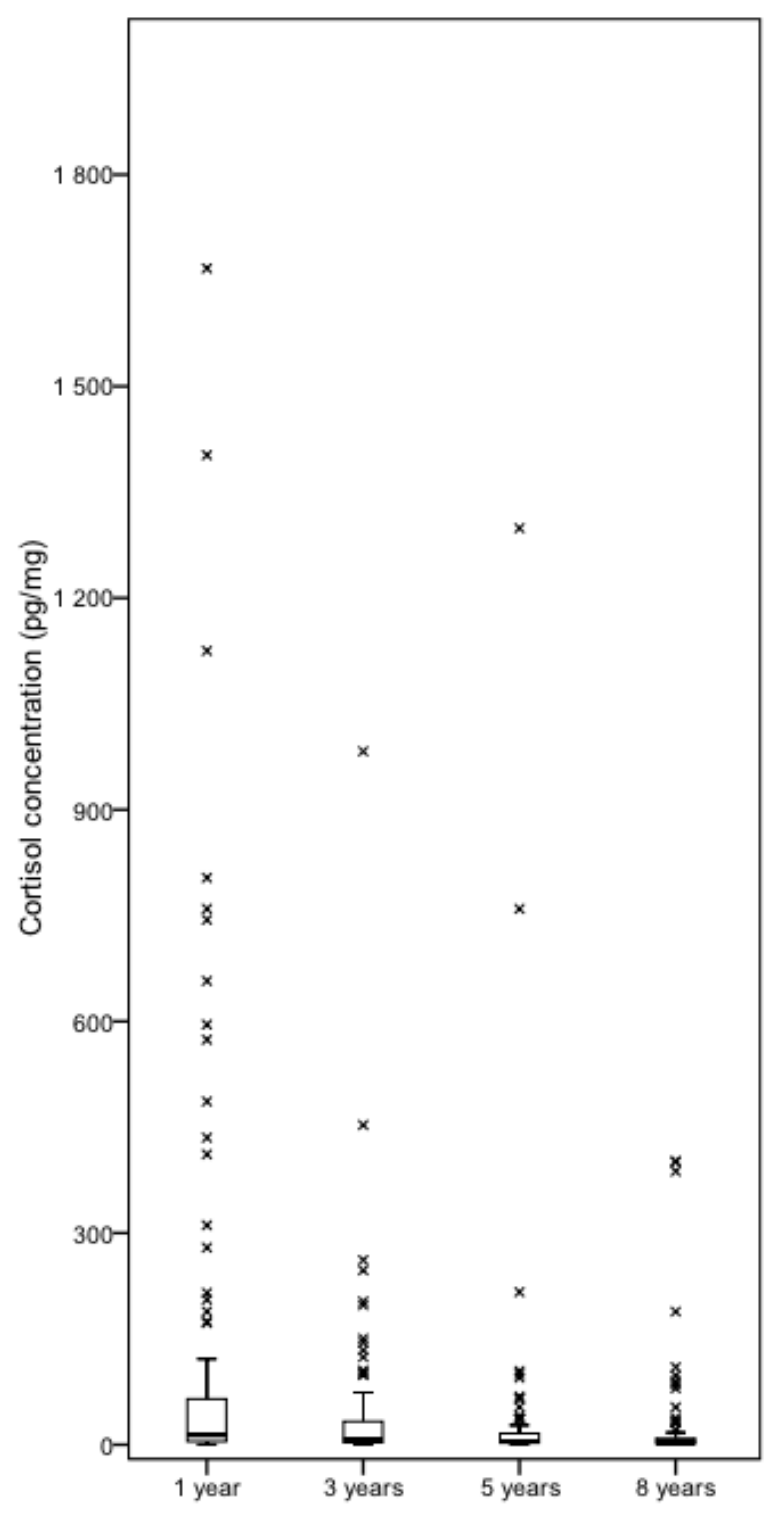

Figure 9. Boxplot of child $(\mathrm{n}=100)$ prospective hair cortisol concentrations $(\mathrm{pg} / \mathrm{mg})$ during early childhood. Box indicates IQR, asterisks indicate outliers ( >1.5 IQR from Q2). 


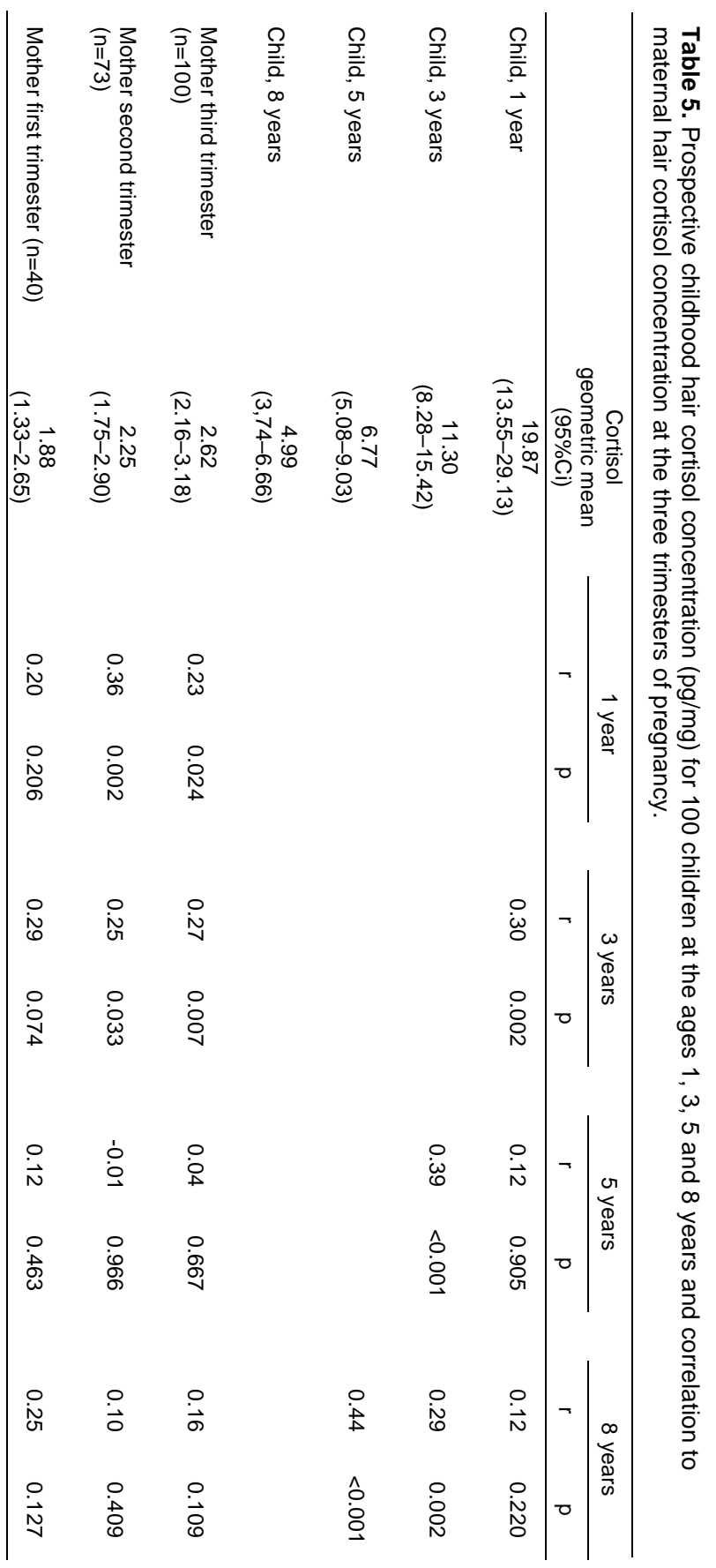




\section{Cortisol in hair socio-demographic factors}

Cortisol levels of children at one year of age and perinatal and socio-demographic factors with sample size ten or above were investigated. Gender (40 boys and 60 girls) had no effect on cortisol levels. Higher birth weight, inappropriate size for gestational age, residence type apartment, and living in an urban area were all significantly correlated to cortisol concentration in hair at a univariate level. Three of these, all but living in an urban area, were also statistically significant in the multivariate analyses. One child was prematurely born; excluding it from the analyses did not significantly change the results. One child whose mother reported a lack of social support during pregnancy had a cortisol concentration of $1667 \mathrm{pg} / \mathrm{mg}$, and the only two children with single mothers had concentrations of 189 and $759 \mathrm{pg} / \mathrm{mg}$ (compared with the median for all children of $13.6 \mathrm{pg} / \mathrm{mg}$ at year 1 ). These cases were not overlapping. Of the two children with a single mother, the mother of the one with a concentration of $759 \mathrm{pg} / \mathrm{mg}$ was also young. Three children, who were attending a day-care centre before the age of one, also had high levels of 759 (the same child as above with single, young mother), 744, and $487 \mathrm{pg} / \mathrm{mg}$. Furthermore, four mothers smoked during pregnancy, giving corresponding levels of 744 (also day-care centre before year 1), 311, 3.2, and $2.4 \mathrm{pg} / \mathrm{mg}$ among the children. Finally, six mothers reported serious life events, and their children had 86.5, 22.6, 8.0, 4.2, 2.4, and $0.8 \mathrm{pg} / \mathrm{mg}$ in raw hair cortisol concentrations.

\section{Paper IV}

There was no difference in logarithmized cortisol levels with respect to gender (boys=2.45 and girls=2.79 pg/mg) or weight. An association between vulnerability and lower birth weight and birth height for females was found. The reference group of female babies with no vulnerability in the family had a mean weight of $3570 \mathrm{~g}$, those with 2 items had a mean weight of $3459 \mathrm{~g}$ $(\mathrm{p}=0.023)$, and those with $3+$ items had a mean weight of $3413 \mathrm{~g}(\mathrm{p}=0.027)$. 
Children with $3+$ items were also shorter at birth than the reference group, with a mean height of $49.8 \mathrm{~cm}$ versus $50.4 \mathrm{~cm}(\mathrm{p}=0.035)$.

\section{Psychosocial vulnerability and cortisol in hair}

An association was found $(\mathrm{r}=0.22, \mathrm{p}=0.002)$ between vulnerability and logarithmized cortisol concentrations in hair, as illustrated in figure 10. When adjusting for gender and small for gestational age (SGA), vulnerability was still solely independently significant $(B=0.40, p<0.0001)$. Vulnerability had a general tendency towards a dose response-like increase in cortisol concentrations; zero items ( $\mathrm{n}=33$ ) gave mean $1.90 \mathrm{pg} / \mathrm{mg}$ (95\% CI=0.91-2.89); one item (46) gave 2.18 (2.17-4.16); three items (49) gave 2.76 (2.12-3.41); four items (24) gave 2.82 (1.99-3.65); five (10) gave 3.86 (2.46-5.26) and six items $(\mathrm{n}=2)$ gave mean 7.21 out of the values 6.88 and $7.54 \mathrm{pg} / \mathrm{mg}$. Out of the 11 single dichotomous items, a significant difference in mean cortisol values was found for two variables: mother unemployed or on sick leave during pregnancy $(\mathrm{p}=0.041)$ and living in an apartment compared to a house $(\mathrm{p}=0.031)$, see table 6 . Also, all but one of the items (father's occupation), exhibited higher mean cortisol levels in the exposed group, although non-significant.

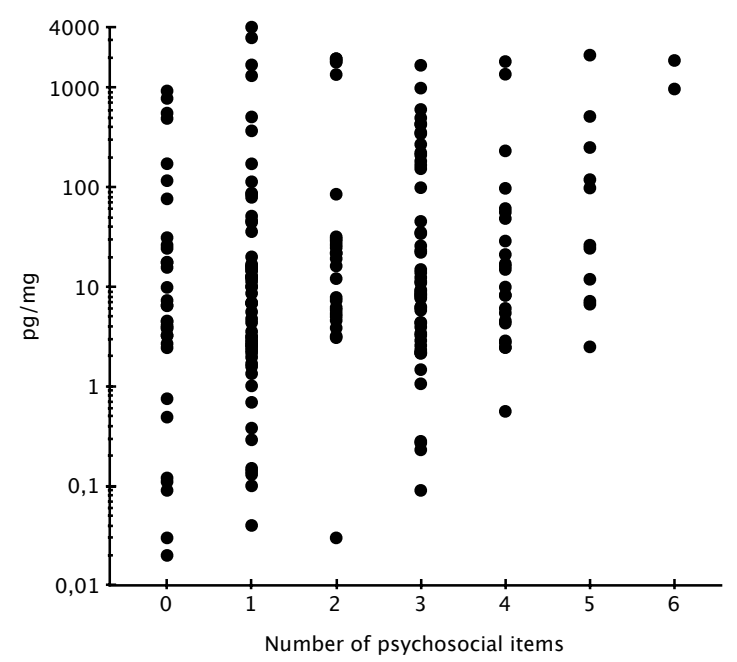

Figure 10. Prenatal psychosocial vulnerability and hair cortisol concentration at one year $(n=209)$. 
Table 6. Prenatal psychosocial vulnerability, single items and hair cortisol concentration (log $\mathrm{pg} / \mathrm{mg}$ ) at age one year.

\begin{tabular}{|c|c|c|c|c|}
\hline Psychosocial exposure & & $\mathrm{n}$ & $\begin{array}{l}\text { Cortisol mean } \\
\qquad(95 \% \mathrm{Cl})\end{array}$ & $p^{a}$ \\
\hline $\begin{array}{l}\text { Vulnerability score } \\
\text { (number of single items) }\end{array}$ & & 209 & $2.62(2.28-2.96)$ & $0.002^{b}$ \\
\hline \multicolumn{5}{|l|}{ Single items } \\
\hline Mother's marital status & $\begin{array}{l}\text { In a relationship } \\
\text { Single }\end{array}$ & $\begin{array}{c}191 \\
18\end{array}$ & $\begin{array}{l}2.43(2.28-3.00) \\
2.64(1.43-3.43)\end{array}$ & 0.733 \\
\hline Mother's occupation & $\begin{array}{l}\text { Working } \\
\text { Unemployed/sick-leave }\end{array}$ & $\begin{array}{c}162 \\
47\end{array}$ & $\begin{array}{l}2.43(2.05-2.82) \\
3.27(2.54-4.00)\end{array}$ & 0.041 \\
\hline Father's occupation & $\begin{array}{l}\text { Working } \\
\text { Unemployed/sick-leave }\end{array}$ & $\begin{array}{c}193 \\
16\end{array}$ & $\begin{array}{l}2.62(2.27-3.98) \\
2.57(1.39-3.77)\end{array}$ & 0.941 \\
\hline Residence type & $\begin{array}{l}\text { Villa } \\
\text { Apartment }\end{array}$ & $\begin{array}{c}73 \\
136\end{array}$ & $\begin{array}{l}2.12(1.50 \mathrm{v} 2.73) \\
2.89(2.49-3.29)\end{array}$ & 0.031 \\
\hline Father's educational level & $\begin{array}{l}\text { College or university } \\
\text { High School/9-year }\end{array}$ & $\begin{array}{c}170 \\
39\end{array}$ & $\begin{array}{l}2.47(2.08-2.86) \\
3.28(2.57-3.99)\end{array}$ & 0.067 \\
\hline Mother's educational level & $\begin{array}{l}\text { College or university } \\
\text { High School/9-year }\end{array}$ & $\begin{array}{c}182 \\
27\end{array}$ & $\begin{array}{l}2.55(2.17-2.92) \\
3.13(2.39-3.87)\end{array}$ & 0.257 \\
\hline Foreign origin & $\begin{array}{l}\text { None or one parent } \\
\text { Both parents }\end{array}$ & $\begin{array}{c}191 \\
18\end{array}$ & $\begin{array}{l}2.54(2.19-2.88) \\
3.55(2.19-4.91)\end{array}$ & 0.096 \\
\hline Maternal serious life event & $\begin{array}{l}\text { No } \\
\text { Yes }\end{array}$ & $\begin{array}{c}174 \\
35\end{array}$ & $\begin{array}{l}2.57(2.20-2.95) \\
2.88(2.01-3.66)\end{array}$ & 0.523 \\
\hline Maternal lack of support & $\begin{array}{l}\text { No } \\
\text { Yes }\end{array}$ & $\begin{array}{c}208 \\
1\end{array}$ & $\begin{array}{c}2.60(2.25-2.93) \\
6.88(-)\end{array}$ & - \\
\hline Mother feeling safe ${ }^{c}$ & $\begin{array}{l}\text { Yes } \\
\text { No }\end{array}$ & $\begin{array}{c}204 \\
5\end{array}$ & $\begin{array}{l}2.59(2.25-2.93) \\
4.01(2.08-6.93)\end{array}$ & - \\
\hline $\begin{array}{l}\text { Mother worried about child } \\
\text { falling ill with serious disease }\end{array}$ & $\begin{array}{l}\text { No } \\
\text { Yes }\end{array}$ & $\begin{array}{c}116 \\
93\end{array}$ & $\begin{array}{l}2.37(2.92-2.82) \\
2.94(2.43-3.45)\end{array}$ & 0.099 \\
\hline
\end{tabular}




\section{Psychosocial vulnerability and health outcome}

The cumulative incidence was analysed for the 14 most common diagnoses, ranging from 0.81 (acute upper respiratory infections) to 0.09 (urticaria). Incidence rates below this were too low for reliable statistical analyses. Comparing the mean vulnerability in diagnosed versus undiagnosed groups, it was significantly higher for diagnosed children in 12 out of the 14 ICD10 groupings. After adjusting for gender and SGA, ten diagnoses were still significant $(B=1.92, p<0.0001)$, see table 7 . Gender was also independently significant in some cases, among boys: acute upper respiratory infections $(\mathrm{p}=0.002)$; injury, poisoning and certain other consequences of external causes $(\mathrm{p}<0.0001)$ and asthma $(\mathrm{p}=0.018)$. Among girls, one diagnosis was more common, urinary tract infections $(\mathrm{p}<0.0001)$. Moreover, vulnerability correlated to the number of different diagnoses $(\mathrm{r}=0.15, \mathrm{p}<0.0001)$. An increase in vulnerability was associated and graded to a corresponding rise in OR for most diagnoses, although they were only significant among those in the highest category of vulnerability, with a few exceptions. One exception to this general tendency was for urinary tract infections, where having some degree of vulnerability increased all of the ORs about twofold. The largest increases in ORs compared to the reference group, with a more than twofold increase in the $3+$ category, were seen in the following diagnoses: viral infections of unspecified site, intestinal infectious disease and urticaria. Somewhat smaller but still significant ORs were seen in the two most common diagnoses: upper respiratory infections and otitis media. 
Table 7. Prenatal psychosocial vulnerability and the risk for the 14 most common childhood diagnoses prospectively until age 10 years $(n=1876)$.

\begin{tabular}{|c|c|c|c|c|c|c|}
\hline \multirow{2}{*}{ Diagnoses (ICD-10) } & \multirow{2}{*}{$\begin{array}{l}\text { Psychosocial } \\
\text { items }\end{array}$} & \multirow{2}{*}{ n (\%) } & \multicolumn{2}{|c|}{ Diagnose risk } & \multirow{2}{*}{$\mathrm{p}^{\mathrm{a}}$} & \multirow{2}{*}{$p^{b}$} \\
\hline & & & OR & $95 \% \mathrm{Cl}$ & & \\
\hline $\begin{array}{l}\text { Acute upper respiratory } \\
\text { infections (J00-J06) }\end{array}$ & $\begin{array}{c}0 \\
1 \\
2 \\
3+\end{array}$ & $\begin{array}{l}346(78) \\
603(79) \\
368(83) \\
196(87)\end{array}$ & $\begin{array}{l}\text { ref } \\
1.06 \\
1.34 \\
1.83\end{array}$ & $\begin{array}{c}- \\
0.80-1.41 \\
0.96-1.87 \\
1.17-2.86\end{array}$ & 0.003 & 0.004 \\
\hline Otitis media (H65-H67) & $\begin{array}{c}0 \\
1 \\
2 \\
3+\end{array}$ & $\begin{array}{l}288(65) \\
496(65) \\
298(67) \\
172(76)\end{array}$ & $\begin{array}{l}\text { ref } \\
1.00 \\
1.09 \\
1.71\end{array}$ & $\begin{array}{c}- \\
0.79-1.28 \\
0.83-1.44 \\
1.19-2.46\end{array}$ & 0.009 & 0.007 \\
\hline Injury (S00-T98) & $\begin{array}{c}0 \\
1 \\
2 \\
3+\end{array}$ & $\begin{array}{l}247(56) \\
418(55) \\
271(61) \\
138(62)\end{array}$ & $\begin{array}{l}\text { ref } \\
0.96 \\
1.24 \\
1.24\end{array}$ & $\begin{array}{c}- \\
0.76-1.22 \\
0.95-1.61 \\
0.90-1.76\end{array}$ & 0.048 & 0.053 \\
\hline $\begin{array}{l}\text { Viral infections of } \\
\text { unspecified site (B34) }\end{array}$ & $\begin{array}{c}0 \\
1 \\
2 \\
3+\end{array}$ & $\begin{array}{l}99(22) \\
210(28) \\
138(31) \\
85(38)\end{array}$ & $\begin{array}{l}\text { ref } \\
1.32 \\
1.56 \\
2.10\end{array}$ & $\begin{array}{l}-\overline{1.01-1.74} \\
1.16-2.11 \\
1.48-2.97\end{array}$ & $<0.0001$ & $<0.0001$ \\
\hline $\begin{array}{l}\text { Infections of the skin } \\
\text { (L00-L08) }\end{array}$ & $\begin{array}{c}0 \\
1 \\
2 \\
3+\end{array}$ & $\begin{array}{c}123(28) \\
205(27) \\
126(28) \\
66(29)\end{array}$ & $\begin{array}{l}\text { ref } \\
0.96 \\
1.03 \\
1.07\end{array}$ & $\begin{array}{c}-\overline{0} \\
0.74-1.26 \\
0.77-1.38 \\
0.75-1.53\end{array}$ & 0.618 & - \\
\hline $\begin{array}{l}\text { Other acute lower } \\
\text { respiratory infections } \\
(\mathrm{J} 20-\mathrm{J} 22)\end{array}$ & $\begin{array}{c}0 \\
1 \\
2 \\
3+\end{array}$ & $\begin{array}{l}81(18) \\
133(18) \\
92(21) \\
55(24)\end{array}$ & $\begin{array}{l}\text { ref } \\
0.95 \\
1.17 \\
1.44\end{array}$ & $\begin{array}{c}- \\
0.70-1.28 \\
0.84-1.62 \\
0.98-2.12\end{array}$ & 0.038 & 0.029 \\
\hline Conjunctivitis (H10) & $\begin{array}{c}0 \\
1 \\
2 \\
3+\end{array}$ & $\begin{array}{l}69(16) \\
137(18) \\
89(20) \\
52(23)\end{array}$ & $\begin{array}{l}\text { ref } \\
1.19 \\
1.36 \\
1.62\end{array}$ & $\begin{array}{c}- \\
0.87-1.63 \\
0.96-1.92 \\
0.98-2.12\end{array}$ & 0.012 & 0.020 \\
\hline $\begin{array}{l}\text { Dermatitis and eczema } \\
\text { (L20-L30) }\end{array}$ & $\begin{array}{c}0 \\
1 \\
2 \\
3+\end{array}$ & $\begin{array}{l}65(15) \\
123(16) \\
82(18) \\
57(25)\end{array}$ & $\begin{array}{l}\text { ref } \\
1.12 \\
1.31 \\
1.96\end{array}$ & $\begin{array}{l}-\overline{-} \\
0.81-1.55 \\
0.92-1.88 \\
1.32-2.92\end{array}$ & 0.001 & 0.032 \\
\hline $\begin{array}{l}\text { Intestinal infectious } \\
\text { diseases (A00-A09) }\end{array}$ & $\begin{array}{c}0 \\
1 \\
2 \\
3+\end{array}$ & $\begin{array}{l}52(12) \\
102(13) \\
74(17) \\
54(24)\end{array}$ & $\begin{array}{l}\text { ref } \\
1.16 \\
1.50 \\
2.36\end{array}$ & $\begin{array}{l}-\overline{1}-18-2.92 \\
1.34-3.51 \\
1.03-3.25\end{array}$ & $<0.0001$ & 0.002 \\
\hline $\begin{array}{l}\text { Urinary tract infections } \\
(\mathrm{N} 30, \mathrm{~N} 34, \mathrm{~N} 39.0)\end{array}$ & $\begin{array}{c}0 \\
1 \\
2 \\
3+\end{array}$ & $\begin{array}{l}27(6) \\
82(11) \\
55(12) \\
24(11)\end{array}$ & $\begin{array}{l}\text { ref } \\
1.86 \\
2.17 \\
1.83\end{array}$ & $\begin{array}{l}-\overline{1}-18-2.92 \\
1.34-3.51 \\
1.03-3.25\end{array}$ & 0.013 & 0.003 \\
\hline $\begin{array}{l}\text { Viral infections } \\
\text { characterised by skin and } \\
\text { mucous lesion (B00-B09) }\end{array}$ & $\begin{array}{c}0 \\
1 \\
2 \\
3+\end{array}$ & $\begin{array}{l}36(8) \\
66(9) \\
52(12) \\
28(12)\end{array}$ & $\begin{array}{l}\text { ref } \\
1.07 \\
1.50 \\
1.60\end{array}$ & $\begin{array}{l}- \\
0.70-1.64 \\
0.96-2.34 \\
0.95-2.70\end{array}$ & 0.021 & 0.061 \\
\hline Pneumonia (J12-J18) & $\begin{array}{c}0 \\
1 \\
2 \\
3+\end{array}$ & $\begin{array}{c}40(9) \\
66(9) \\
46(10) \\
27(12)\end{array}$ & $\begin{array}{l}\text { ref } \\
0.96 \\
1.16 \\
1.37\end{array}$ & $\begin{array}{l}-\overline{0}-1.44 \\
0.74-1.81 \\
0.82-2.29\end{array}$ & 0.160 & - \\
\hline Asthma (J45) & $\begin{array}{c}0 \\
1 \\
2 \\
3+\end{array}$ & $\begin{array}{c}32(7) \\
63(8) \\
48(11) \\
29(13)\end{array}$ & $\begin{array}{l}\text { ref } \\
1.16 \\
1.55 \\
1.89\end{array}$ & $\begin{array}{c}-\overline{0} \\
0.77-1.80 \\
0.97-2.48 \\
1.11-3.21\end{array}$ & 0.006 & 0.004 \\
\hline Urticaria (L50) & $\begin{array}{c}0 \\
1 \\
2 \\
3+\end{array}$ & $\begin{array}{c}29(7) \\
64(8) \\
47(11) \\
30(13)\end{array}$ & $\begin{array}{l}\text { ref } \\
1.31 \\
1.69 \\
2.19\end{array}$ & $\begin{array}{c}- \\
0.83-2.06 \\
1.04-2.73 \\
1.27-3.74\end{array}$ & 0.002 & 0.016 \\
\hline
\end{tabular}

${ }^{a}$ Mean vulnerability in diagnosed versus undiagnosed groups, independent samples t-test.

${ }^{b}$ Adjusted for gender and size for gestational age, binary regression. 


\section{Distribution in the twin cities}

Additional data from this study but not included in the final submitted paper are presented below.

The distribution of vulnerability factors in the population and in the whiteand blue-collar twin cities are listed in table 8. Four of the factors were significantly more prevalent in the blue-collar city: mother unemployed or on sick leave during pregnancy $(\mathrm{p}=0.002)$, father unemployed or on sick leave the year before pregnancy $(\mathrm{p}=0.003)$, mother's highest level of education only elementary school $(\mathrm{p}=0.001)$ and mother worried over the possibility of child falling ill with serious disease ( $\mathrm{p}=0.039$ ). The mean number of vulnerability factors in the family was 1.23 in the white-collar city and 1.40 in the blue-collar city $(\mathrm{p}=0.001)$. No single family had more than seven vulnerability factors, and the majority of families had none or only one factor.

The cumulative incidence of the 14 most common diagnoses in our sample during the ten-year follow-up in regard to sex and the twin cities is shown in table 9. Four diagnoses were more common among boys: acute upper respiratory infections ( $\mathrm{p}=0.007)$; injury, poisoning and certain other consequences of external causes $(\mathrm{p}=0.001)$; other acute lower respiratory infections $(\mathrm{p}=0.038)$ and asthma $(\mathrm{p}=0.011)$. One diagnosis, urinary tract infections $(\mathrm{p}=0.001)$, was more common among girls. Five diagnoses had a significantly higher incidence in the bluecollar city: acute upper respiratory infections $(\mathrm{p}=0.018)$; otitis media $(\mathrm{p}=0.001)$; viral infections of unspecified site ( $\mathrm{p}=0.005)$; intestinal infectious diseases $(\mathrm{p}=0.003)$ and pneumonia $(\mathrm{p}=0.002)$. None of the analysed diagnoses had a higher cumulative incidence in the white-collar city. 


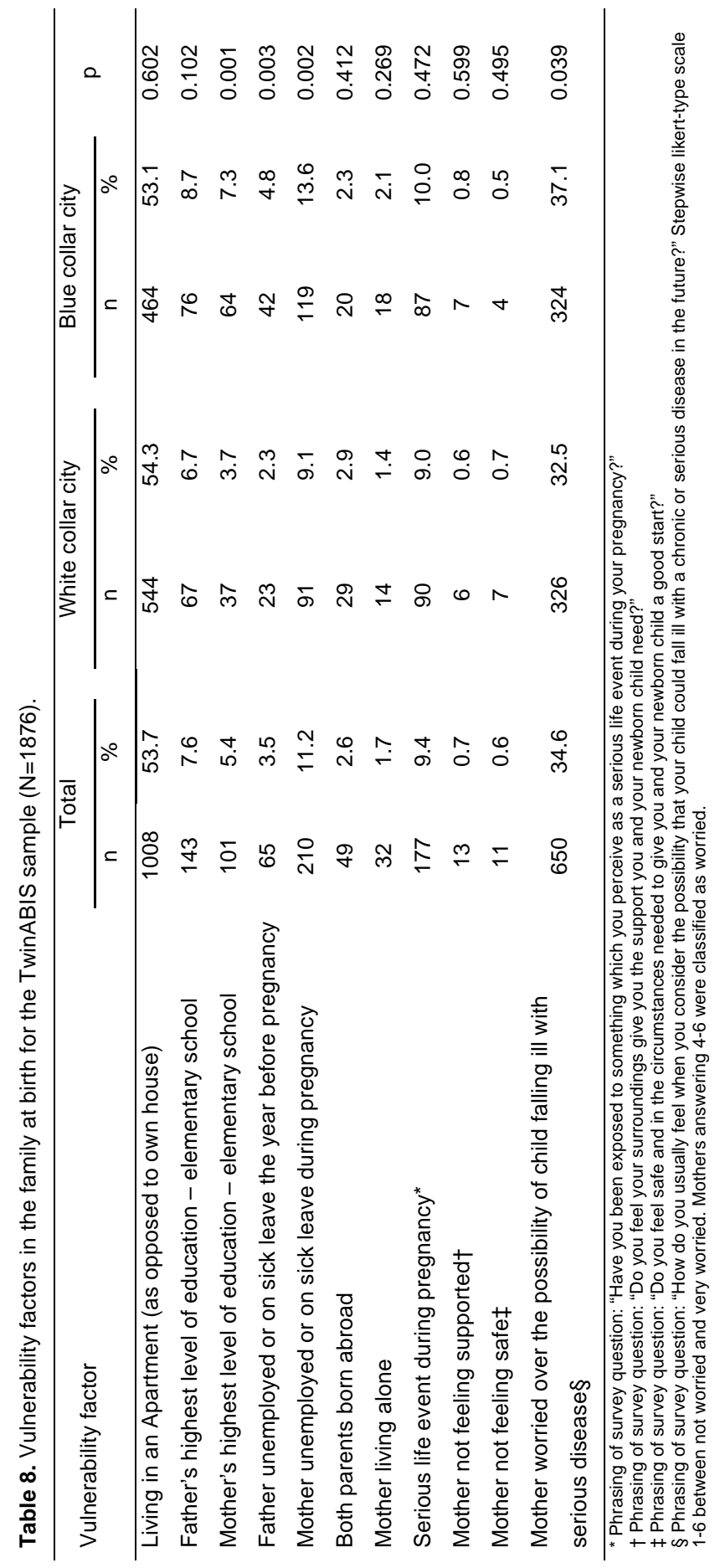




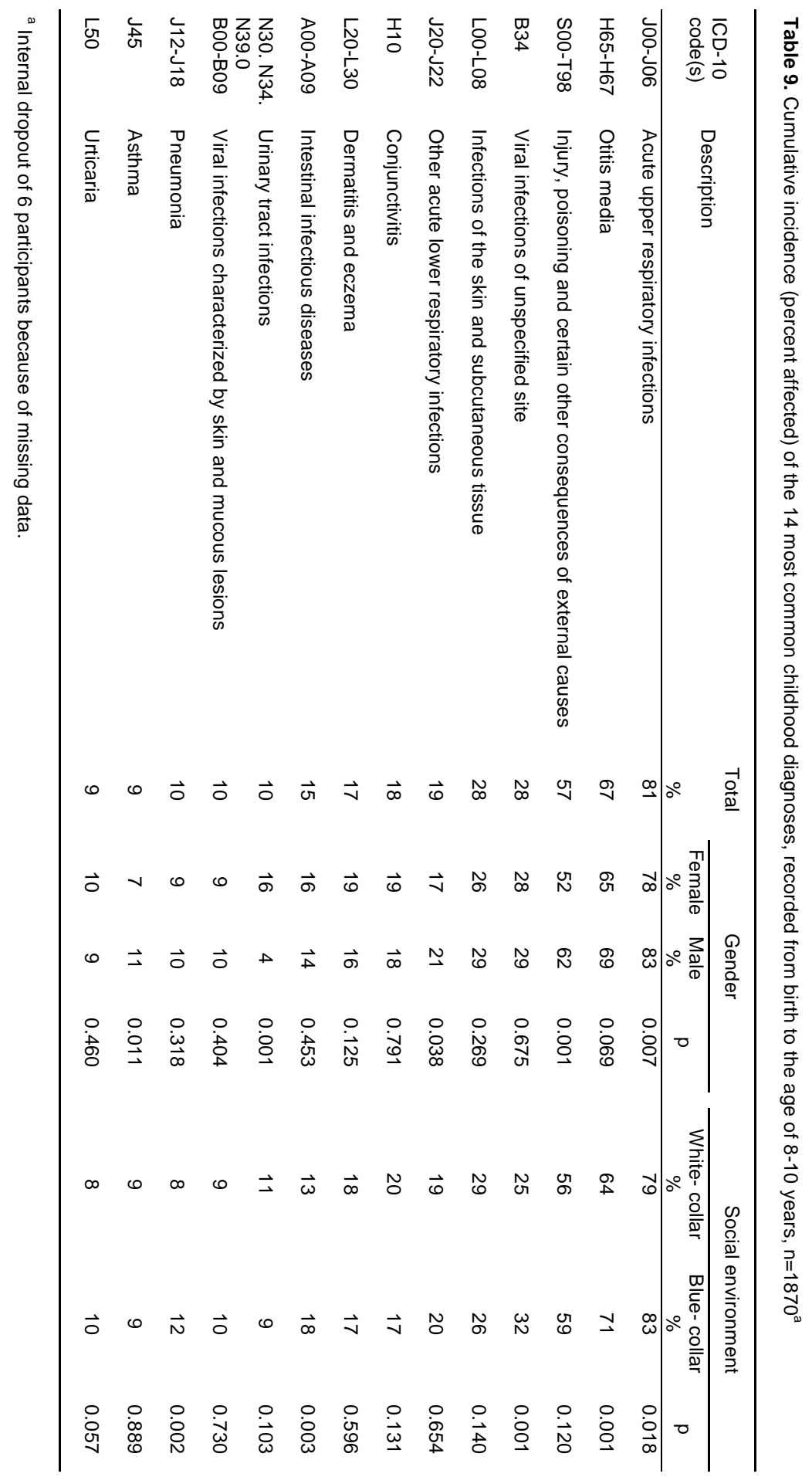




\section{DISCUSSION}

\section{Main Findings}

This thesis aimed at examining the relationships between psychosocial stress in early life, child health and cortisol in hair as a marker for long-term HPA axis activity.

As shown in Paper I, there appears to be a difference in the risk of diabetesrelated autoimmunity among children living in two different psychosocial environments. Those living in a blue-collar city had high levels of autoantibodies more often than those living in a white-collar city.

In Paper II, the method of measuring cortisol concentrations in hair was developed, which seems to have the potential of becoming a new indicator of long-term HPA axis activity, identifying possible stress exposures with an association to major life stressors.

Paper III shows that, in children from one to eight years of age, cortisol levels in hair are correlated over time, but also associated to maternal hair cortisol levels during pregnancy. This suggests a heritable trait or environmental calibration to maternal HPA axis activity.

Paper IV demonstrates that children born into families fraught with living under disadvantageous psychosocial exposures seem to have increased cortisol levels in hair and are more likely to be affected by diseases common in childhood in a dose-response-like manner. 


\section{Interpretation of Findings}

\section{Early psychosocial exposures and health}

Papers I and IV cover potential health outcomes among children in different psychosocial environments.

As shown in Paper I, there appears to be a difference in the risk of diabetesrelated autoimmunity among children living in two different social environments, even after adjusting for other known risk factors for T1D. ${ }^{79,147-149}$ An important strength in this study was the ability to control a number of other diabetes-related potential confounding factors that had already been studied in the ABIS material. These results have, after Paper I was published, been confirmed at the age of three years, notably though with slightly less difference between the cities, which supports the notion that the differences found did not arise by chance.

A high-titer of an autoantibody may indicate that an autoimmune process has begun, possibly leading to T1D, and is used to identify subjects at risk of developing the disease. The majority of the children who were positive for one of the diabetes-related autoantibodies at one or three years of age will never develop T1D. Consequently, the results in this study imply that psychosocial stress was only associated with the induction of diabetes-related autoimmunity. Nevertheless, these findings support the stress hypothesis concerning the induction of diabetes-related autoantibodies as a possible hypothesis among others, and are in line with earlier studies of stress as a possible aetiological factor of T1D. 16,78

Some earlier studies have indeed shown a correlation between psychosocial factors and the risk of T1D, although findings concerning the socio-economic gradient are too inconsistent to allow firm conclusions, ${ }^{80,144,150,151}$ and the difference in public health between the studied cities is marked. ${ }^{137,139}$ But what in the social environment could trigger the induction of autoantibodies? There are many different modulating factors that may covariate in the autoimmune process leading to T1D and the aetiology is unknown. ${ }^{77}$ One could speculate 
that a blue-collar social environment characterized by more widespread economical problems, lower education and higher unemployment rates gives a higher general level of stress in the community. Stress in the close family as a result of a more socially deprived environment could then possibly affect the children's immune system. Although it has been shown that stressful life events precede the development of beta-cell autoantibodies and this could also be valid on the community level. Could it be relevant to introduce a concept like 'community stress' that represents an accumulation of stressful events and negative psychosocial conditions that affects the population in a whole community? Similar mechanisms could contribute to the results in Paper I, possibly shedding light on the unspecified so-called 'black box', introduced by Susser, in disease aetiology between social exposures and autoantibody levels. ${ }^{33}$ Although these results and the difference in levels of autoantibodies between children in the two cities are intriguing, the findings tell us little about the aetiology of T1D and should be seen mainly as hypothesis generating. However, beta-cell autoimmunity in itself indicates that something is wrong with the immune system, since it attacks and destroys own healthy tissues. If someone develops a larger quantity of antibodies than $95 \%$ of all healthy children, it is definitely an abnormal reaction and something has happened with the immune system of that child.

In Paper IV, prenatal detrimental psychosocial exposures resulted in a corresponding increase in the risk of being diagnosed with 12 of the 14 most common childhood diseases, with a general dose-response-like pattern of rising ORs, statistically significant for the most vulnerable children. These results were in line with earlier findings on early stress and poor health in childhood that suggest a relationship between early detrimental psychosocial factors and disease risks. Diagnoses are not a measure of actual disease; however, in Sweden, children with parents of low socio-economic status (SES) are less likely to visit a physician, ${ }^{152}$ and such bias could therefore have made the association even weaker in the present study than it actually is. Most of the childhood diagnoses were common infection diseases, as we did not have enough statistical power to analyse less common childhood diseases. Some possible explanations to this risk difference could, for example, be that the number of siblings and day-care use might expose vulnerable families to 
infectious pathogens to a greater extent. Then again, earlier research on adults by, for example, Cohen show immune cells being unable to respond to hormonal control as well as showing a susceptibility to the common cold among adults suffering from psychosocial stress. ${ }^{153,154}$

\section{Psychosocial factors and cortisol in hair}

Papers II, III and IV all suggest that the measurement of cumulated concentration of cortisol in hair is associated to earlier stressful psychosocial circumstances.

Paper II showed that higher hair cortisol concentrations were found among those reporting that they had experienced serious life events during the last three months, somewhat surprisingly as the Perceived Stress Scale was not significantly associated to cortisol levels. This could be a result of the weakness in the validity of PSS to a time period of three months as mentioned earlier in the method section. A general question is how well the concordance is for humans between perceived stress and the actual individual activity of the HPA axis. Furthermore, there were two other findings in this paper that support the association between psychosocial stressors and levels of cortisol. 1) Four outliers had extremely high cortisol levels and two of them could be reached through open announcement. Although single case findings, both reported severe psychological problems during the last three months, which raises the question whether this new biomarker also may reflect severe psychological illness. 2) Also, when testing every single PSS-item, the question 'In the last month, how often have you felt difficulties were piling up so high that you could not overcome them?' was significant ( $p=0.004$ ) against higher levels of cortisol with a tendency towards exposure-response relationship (not included in final Paper II), arguing for an association to coping with everyday hassles, which in earlier studies has been shown to correlate more to stress as well as health status problems such as depression. ${ }^{155}$ 
In Paper III, an interesting finding relating to the variables reflecting social exposures was that children living in a villa compared to an apartment had lower hair cortisol levels, possibly mirroring differences in the continuous stress exposure of the social environment. ${ }^{20}$ Variables describing the mother's psychosocial circumstances are interesting as they tend to point in the expected direction according to the hypothesis of influence of psychosocial factors on stress in general. However, the number of mothers in the affected groups was small, so these findings should be interpreted with caution and only for generating hypotheses. One mother experiencing lack of support during pregnancy, and the two single mothers had children with very high hair cortisol levels at year 1 (notably not the same mothers). Also, being a very young mother was associated with higher cortisol levels of the child. This is also the case with the three children starting day care before the age of one, who all had higher cortisol levels than the mean. This finding is supported by studies on cortisol in saliva, where cortisol levels among children at day-care centres rose compared to those being at home, possibly reflecting the everyday social challenges in peer groups. ${ }^{156}$ In the current study, educational levels of the parents were not related to hair cortisol levels, in agreement with what Vaghri et al. recently showed. ${ }^{157}$ Nor were parental smoking, foreign origin of the parents or maternal experiences of serious life events during pregnancy associated to higher hair cortisol levels. Cortisol concentrations in hair for the children intercorrelated over ages 1, 3, 5 and 8. Children's cortisol levels at ages 1 and 3 were also correlated to maternal cortisol levels during pregnancy. This suggests that the physiological stress response has a very early set point, possibly genetic, which affects the levels of cortisol output later in life. Yet another explanation could be environmental calibration to maternal cortisol levels. A genetic background for the stress response is plausible but not thoroughly investigated. ${ }^{158,159}$ More recent theories suggest that epigenetics could be involved in modulating the transgenerational effects of stress. ${ }^{160}$ One could hypothesize that this association could be part of the transmission gap in the attachment theory, assisting in the development of the child's own behavioural and physiological regulatory systems e.g. the stress response, ${ }^{161}$ perhaps explaining some of the strong association between parental attachment and infant attachment. ${ }^{162,163}$ Or it could be a reflection of the quality of the maternal 
care, known to have a great impact on lifelong stress reactivity via 'programming' of the neuroendocrine stress response in rodent offspring. ${ }^{164,165}$ Furthermore, cortisol levels at year 1 had high variability, with very high values and a wider interquartile range compared to those at 3 years, narrowing down with every subsequent measure at 5 and 8 years. This supports the theory that the stress response system seems to mature over time and is consistent with previous studies on cortisol in saliva and serum. ${ }^{100,101}$

As shown in Paper IV, added prenatal detrimental psychosocial vulnerability was associated to increased levels of cortisol in hair in a dose-response-like manner. When adjusting for gender and inappropriate SGA, vulnerability was still solely and independently significant. $(B=0.40, p<0.0001)$ This has, to our knowledge, never been shown before; supporting the theory behind the vulnerability construct and the allostatic load hypothesis stating that the accumulation of adversities matters and that a dysregulation of the physiological stress system is one plausible mechanism in how psychosocial exposures affect health. Supporting these results is a study on patients with PTSD, where levels of cortisol in hair and the number of lifetime traumatic events seemed to have a dose-response relationship. ${ }^{128}$ Even though the vulnerability construct could be developed further, including more validated variables at different levels of operation, as well as improving the method for measuring cortisol in hair, there is a probability that some of the individuals actually could have an attenuated stress response. There is recent evidence that exposure to intense stimuli could in some cases dampen HPA axis reactivity, and inconsistent reports of socio-ecomomic status (SES). ${ }^{166-168}$ However, this has been shown among adults and again with methods measuring cortisol levels in saliva and blood, which makes comparison to cortisol in hair difficult. One could speculate that a developing child has a more reactive stress response compared to an adult (as shown in Paper III), due to being less mature and having experienced less stress. But then there are extreme cases, such as traumatized apathetic refugee children, that seem to have a blunted stress response. ${ }^{169}$ Furthermore, two out of the eleven single psychosocial items were significantly correlated to elevated cortisol levels of the child (mother unemployed or on sick leave during pregnancy and living in an apartment compared to a house). In eight of the remaining nine items, mean cortisol levels were higher in 
the exposed group, although not significantly so. These findings further support the possible association between psychosocial factors and heightened HPA axis activity, thus indicating that cortisol in hair mirrors the continuous stress load in the daily social environment.

The widespread positive correlation of the different psychosocial factors to cortisol in hair studied in this thesis, as well as the dose-response-like effect, suggest that there is an association between the accumulative nature of adverse psychosocial factors and increased HPA axis activity measured through hair cortisol concentrations, at least at group level. Supporting this is research published in recent years in this expanding field of interest. As an example, shift workers have a higher risk of cardiovascular disease, ${ }^{170}$ and indeed, there seem to be elevated levels of cortisol in hair among shift workers. ${ }^{120}$ Other studies have found association with, for example, unemployment and parental income. ${ }^{121,123}$ Psychosocial factors like SES are powerful predictors of adult cardiovascular morbidity ${ }^{171}$ - interestingly, some studies have found an association between cortisol levels in hair and obesity, diabetes type 2, level of heart failure as well myocardial infarction. ${ }^{130-134}$ Therefore, given the prolonged nature of the exposure to a stressful psychosocial environment and its detrimental effects on health, the novel biomarker of cortisol in hair could prove to be of major importance in this area of research.

In contrast, studies focusing on the individual's perception of stress or selfreported stress-related measures have mostly found none or diverging associations. The lack of covariance could possibly be explained by lag effects caused by different time exposures of the retrospective assessment, in Paper II illustrated by the fact that the perceived stress scale is validated only for the preceding four weeks while measuring cortisol levels representing the previous couple of months, as well as problems with recall bias. ${ }^{172}$ This could be part of the explanation as to why Papers II and III also showed diverging results concerning the variable serious life events, where there was a significant correlation in Paper II based on 99 studied students, but no such significant association was found when analysing the 100 pregnant mothers in Paper III. Although a small study, one interesting report is on the positive association of effort-reward imbalance among 39 female day-care teachers $(r=0.33, p=$ 
0.006) to cortisol levels in hair, but no association with either the effort or the reward scale separately. ${ }^{173}$ It seems that more research is needed to find or develop appropriate tools to assess perceived stress, protective factors, personality aspects and the psychological effects on the long-term assessment of the physiological stress response that cortisol in hair seems to constitute.

\section{Study Limitations and Methodological Considerations}

\section{Design and analysis}

Three out of four studies in this thesis were based on the ABIS study, with the general strength of a true prospective design and the relatively high initial participation rate $(79 \%)$. The sample was representative of Sweden concerning the parents' education and origin at the time (Statistics Sweden, 1999), but it is uncertain whether it has changed over time. A strength that lies in the cohort design is that the maternal responses are unbiased concerning the different dependent variables, the mothers had no knowledge of the outcomes, such as autoantibodies, hair cortisol concentrations and later diagnoses for their child. Furthermore, the large sample size requires one to be cautious when interpreting the results, as small but significant differences may not always be clinically relevant. As such, although there is a very strong scientific advantage that lies within a prospective framework and high participant rate, it does not necessarily implicate that all correlations found are causal in nature and clinically significant. To be humble, correlations should mainly be considered as associations.

A general limitation for prospective studies is the tendency of diminishing participation rates over time. The dropout rates increase for each new followup. This is also evident in the ABIS study, although the follow-up rate of $67 \%$ (completed questionnaires) at 1 year must be considered acceptable. However, as shown in Paper IV, we have linked data of health-care utilization and ICDdiagnosis from a health-care register to fill up the prospective dropout gap. 
There is some risk in prospective studies of possible bias due to social selection against the background of diminishing participating rates over time. The responses received might be the opinions of a motivated section of the sample, possibly giving an underrepresentation of individuals with lower SES. But it could also be that those with problems are more motivated to participate. In general, the least and most advantageous social groups tend not to participate in studies. ${ }^{174}$

How to handle outliers is an intriguing question. If outliers reflect measurement errors they should be omitted from further analysis. However, the procedure in our laboratory is that if outliers are detected, their biological samples are replicated and analysed at two independent occasions to ensure no measurement error had occurred. The participants with extremely high levels of cortisol in hair i.e. outliers, were handled in two different ways in the papers, which calls for an explanation. In Paper II, where adults were tested for cortisol concentrations in hair, we found four outliers, which were excluded from the statistical analysis, but two of them were possible to followup by an interview. This follow-up with an interview revealed important case findings. In Papers III and IV, when cortisol levels in children were measured, we also found outliers. These were included in the statistical analysis after they were log-transformed. We found that the biological variability seemed to be greater in young children especially during their first year of life, which was also reported in earlier reports on cortisol levels in blood and saliva. Possibly the regulation of their cortisol response is not sufficiently calibrated at a very young age. The outliers of cortisol in hair included in Papers III and IV were not considered as measurement errors. Not including them would therefore have risked introducing selection bias into the novel sample of cortisol in hair, and were consequently included, although all values were logtransformed in the statistical analysis.

In Paper IV, only participants who had completed answers on each of the 11 items in the composite vulnerability scale were included. There is a possible underrepresentation of individuals in the higher categories of vulnerability i.e. the distribution is not so even. Possibly this is reflecting the actual situation, with the risk of being affected by many of these single vulnerability factors 
being quite rare in the population. Paper II is not based on the ABIS material, but deals with students around 20 years of age. They do not represent the general population but rather a selective group of young students, which could be seen as a possible limitation of this study. However, one the purpose of Paper II was initially to test the novel biomarker cortisol in hair and its application together with questionnaires.

\section{Psychosocial measures}

The variables used to measure psychosocial exposures in Papers I, III and IV were restricted to the variables already collected in the ABIS questionnaires. These variables are obviously different in nature and represent a variety of psychological, social and environmental dimensions. One could argue that there is a limitation in the measures used as the parents answered the questions rather than the children. Investigating the role of early stress in the development of disease should, if possible, be measured within the same individual. However, besides the obvious ethical, scientific and practical problems of asking small children about their perceived stress, we believe that the parents' answers reflect quite well the psychosocial situation and social environment in which the children live their lives. ${ }^{18}$

The psychosocial variables used are all indicators of a child at psychosocial risk, but the interpretations of associations do not indicate a specific causal relationship. As an example in Paper I, what factors might have caused the difference in autoantibody distribution between children from the blue- and the white-collar city? The twin cities variable is a crude indicator, and a variety of methodological problems could be raised, for example the risk of ecological fallacy. Nevertheless, this variable has been shown in other studies to be a fairly good indicator of the social environment. ${ }^{137,138}$ Another example is the reports of experiences of unspecified serious life events that were measured with a dichotomous yes/no-question. The advantage is that it is a subjective measure where the mother decides whether the event was stressful or not. But, in reality, the perception of how stressful the impact of a life event actually was could differ between mother and child. 
In Paper IV, a scale of psychosocial vulnerability was used. The calculation of this score was not based on any weighing of single variables; the presence of one single vulnerable variable gave simply one point on the score. Even though the items used were crude, the hypothesis was articulated a priori and the general direction of the outcome suggests that the results cannot be explained by chance. In using a composite scale, there is a risk of obscuring associations between individual items that could be seen as confounders. On the other hand, a composite scale could take interactions and potentiating effects into account. ${ }^{46}$ We decided to only include participants with completed answers on each one of the 11 items in our composite vulnerability variable. This reduced the effective response rate to $57 \%$. Looking at the whole TwinABIS sample of $\mathrm{N}=2447$ and the 11 items making up the composite variable, individuals belonging to the vulnerable category in 9 of the items were more likely to have missing answers on other items than those in the not vulnerable category. Thus, our final sample of $\mathrm{N}=1876$ doesn't mirror the true vulnerability status in the population. There is probably an under-representation of individuals in the higher categories of vulnerability and observed associations might have been even more pronounced if these children could have been included. In this study, the consistency of findings, the dose-responselike relationships to disease risk and cortisol levels, as well as no single item being seen as driving the associations, support the theoretical model of vulnerability - that the accumulation of adversities matters.

Paper II is not based on the ABIS questionnaires. The purpose of the independent measures was in this case to scan possible relations between perceived stress and health as well as serious life events with levels of cortisol in hair. The effects of serious life events on physical and mental health have a long research tradition from the early reports by Holmes and Rahe. ${ }^{28}$ This was criticized on methodological grounds concerning the usefulness of generalized magnitude ratings of life events. Later this quite simple measurement, also used in this report, was more widely used. ${ }^{175}$ The PSS used has been validated for a recall period of four weeks, but was used to assess three months of stress in the current study, which is a limitation. Perhaps it would have been better to collect PSS levels at three consecutive months to better reflect the same time interval as the measurement of cortisol levels in hair. Furthermore, there is 
always a risk for recall biases for retrospective self-reports. Possibly, this is more conceivable for reports of perceived stress i.e. changes of emotions, behaviour etc. ${ }^{176}$

\section{Cortisol in hair}

Cortisol in hair is a novel marker of HPA axis activity over time, and as such there is a set of natural features associated with the method. A straightforward restraint is that it is impossible to measure differences in short time interval reactions of an actual stress response to an outer stressor, for that purpose measurement of cortisol in, for example, saliva is preferable. Measurement of cortisol in hair, on the other hand, represents the cumulative concentration of cortisol measured over periods of months or weeks at least. Another obvious restraint is that not everyone has the amount of scalp hair required to measure cortisol levels, ruling out, for example, very thin-haired children as well as bald adults.

There are several possible confounders that should be considered when analysing cortisol in hair. External contamination through, for example, cortisone-containing creams could be a potential confounder. In our studies the ABIS question During pregnancy, did you take any medicine? Cortisone (yes/no) did not alter the results. In Paper II there was no correlation to dyed hair, supported by other studies..$^{94,111,119}$ Bleached or permed hair seemingly shows no effect. ${ }^{132}$ There are also other characteristics that are insufficiently studied, e.g. the effect of gender, race and age. ${ }^{110,111,177,178}$ Other possible limitations of the method are variations in cortisol levels related to cultural differences, coping styles and personalities. ${ }^{179,180}$ Furthermore, we still do not fully understand in what way cortisol becomes incorporated into hair, there are even suggestions that the root of the hair strand could actually produce cortisol, even though the quantities seem to be very small. ${ }^{181,182}$ Contradicting this are a couple of studies on, for example, patients with hypogonadism in which hair testosterone levels follow the pattern of systemic levels and not of ACTH alterations that supposedly would have been the case if ACTH drives the follicular production. ${ }^{183}$ Nevertheless, research so far shows that measuring 
cortisol in hair seems to have a general robustness and stability that speak for its usefulness in further research. ${ }^{113}$ However, some caution is also warranted when interpreting individual cortisol concentrations, despite the fact that the extracts from hair reflect cortisol built into the hair over months. We cannot tell where in a cycle of periods of high- or low-stress exposures an individual is during the time period hair was collected for measuring cortisol concentrations. Cross-sectional measurements of cortisol in hair should therefore, for the time being, mainly be used for group comparisons.

Immunoassay analyses are commonly used for analysis of salivary cortisol as they are relatively easily conducted, are affordable and have become popular when measuring concentrations of cortisol in hair, including the current method. One difficulty is the use of different analysis methodologies by different laboratories. A critical examination of the different enzyme-linked immunosorbent assay (ELISA)-based methods used has begun, as a step towards standardization and uniform interpretation. ${ }^{184}$ Another problem is that the methodology, regardless of the method used, still lacks direct validation research and sufficient methodological rigour. ${ }^{113}$

A particular strength of the current method in this thesis is the ability to reliably analyse cortisol concentrations in samples as minute as $3-5 \mathrm{mg}$ of hair. In comparison, ELISA-based assays have methodologically refined over several years with samples ranging from $100 \mathrm{mg}$ to today where at least $10 \mathrm{mg}$ is required. Mass spectrometric identification is still regarded as the gold standard in forensic hair analysis, ${ }^{185}$ but for this a sample size of about $25 \mathrm{mg}$ is required (Robert Kronstrand 2013. Linköping University, IMH, Division of Drug Research. Personal communication). 


\section{General Conclusions}

Children born into an environment fraught with adverse psychosocial exposures seem to have increased long-term HPA axis activity, which also appears to be persistent throughout early childhood. These children also seem to be more likely to be affected by common childhood diseases. This, together with the widespread and cumulative effect of adverse exposures seen on the different outcomes, support the model of physiologic dysregulation as a plausible pathway of how the duration and number of early detrimental psychosocial exposures act as a trajectory to health disparities. It also suggests that the multiplicity of early adversities is of importance and could be of help in selecting preventive methods at group level.

Moreover, the novel biomarker of cortisol in hair has the potential of becoming a new indicator for retrospective HPA axis activity over periods of months, possibly assessing the biological response to the broader context of an exposure to a stressful psychosocial environment. As such, it provides the possibility to further develop the method, and cortisol in hair could prove to be a very useful aid in the studies of effects of stress on health. It may be especially useful in research among children, with the obvious advantage of easy sample collection, small sample size, and being non-invasive, as well as being non-dependent on stress levels at sample collection. 


\section{Implications for Further Research}

An important result in this thesis is the links between mother and child hair cortisol levels in Paper III. What causes this association? An obvious answer would be environmental calibration or genetic heritability. But there are also some reports on possible epigenetic mechanisms related to stress, e.g. evidence on increased HPA axis activity and epigenetic programming in the male offspring exposed to stress early in the prenatal period, ${ }^{186}$ as well as in studies on mice where chronic stress in male mice results in altered miRNA content of a sperm in association with reduced HPA axis responsiveness in the pup. ${ }^{187}$ Hence, it could be that life-course epidemiology should also include exposures from not only prenatal life, but also from previous generations. ${ }^{188}$ Cortisol in hair as a biomarker of chronic stress could provide an invaluable opportunity for further investigation of the transgenerational mechanisms of epigenetics on the effects on physiological stress activity and stress-related health.

Randomized intervention trials aimed at reducing stress in early childhood by, for example, family intervention programmes at the well-baby clinics with follow-ups, could give leads concerning stress-related health outcomes. This kind of study could simultaneously be aimed at investigating whether the effect of early stress on cortisol regulation is reversible with an intervention, possibly improving the regulation of the biological systems in children. ${ }^{189}$

A thorough investigation of children that have very high levels of cortisol in hair as well those with very low levels is warranted. This could provide leads in trying to understand which protective, salutogenic factors in the stressresilient child (in Swedish 'maskrosbarn') promote a normal stress reaction and in the long run well-being and health. Furthermore, one could gain information on what kind of circumstances may cause a blunt stress response.

The psychosocial vulnerability scale used in this thesis is promising, but needs to be elaborated further, possibly leading to a standardized scale, and could, in clinical and preventive child health settings prove useful. 
Immunoassay analyses of hair cortisol concentration need further validation in general, and current RIA method used in particular. This could be done, for example against mass spectrometry, but also against other sources of known levels of cortisol concentrations to affirm reflective cortisol secretion over extended periods of time. Moreover, other areas of interest could concern possible confounding influences of, for example, environmental exposures and use of pharmaceuticals.

\section{Research possible within the ABIS-study}

An outline of possible future research within the existing ABIS-study could be the following:

- Cortisol levels in hair and psychosocial vulnerability among children that have developed type 1 diabetes.

- General follows-ups on the TwinABIS subsample concerning psychosocial factors, cortisol levels and health outcome.

- Further development of the cortisol in hair method towards smaller hair samples so as to be able to measure even smaller already collected hair samples in the ABIS bio bank.

- Investigation of whether prenatal vulnerability has a stand-alone effect on HPA axis activity or whether it simply mirrors future vulnerability by examining psychosocial circumstances in the follow-ups.

- Case-control studies on specific sub-groups of children, e.g. those that at an early age had extreme levels of cortisol in hair or high vulnerability. 


\section{POPULÄRVETENSKAPLIG SAMMANFATTNING}

Den tidiga psykosociala miljön som barn växer upp i har visat sig vara viktig för hur hälsan utvecklas under barndomen men även långt upp i vuxen ålder. En möjlig förklarande biologisk mekanism mellan den psykosociala miljön och senare ohälsa kan vara att fysiologiska reaktionsmönster i kroppen, exempelvis det komplexa samspelet mellan hjärna, hormoner och immunsystem, förändras när man utsätts för tidig stress vilket påverkar kroppens förmåga att hantera sjukdomar. Människors stressnivåer mäts ofta genom att analysera nivåerna av stresshormonet kortisol i exempelvis saliv och blod, men dessa metoder mäter bara hur stressad individen är i själva mät-ögonblicket. $\mathrm{Nu}$ finns en ny metod där man kan mäta kortisol i människors hår som till skillnad mot tidigare metoder återspeglar stressnivåerna över längre perioder, som månader, och även bakåt i tiden, ungefär som årsringarna på ett träd.

Syftet med denna avhandling var att undersöka om det fanns några samband mellan tidig utsatthet för psykosocial stress och barnets senare hälsa, samt om detta påverkar barnets stressnivåer över längre tidsperioder under uppväxten, genom att mäta nivåer av kortisol i hår.

Delstudierna i den här avhandlingen bygger till stor del på ABIS-studien (alla barn i sydöstra Sverige), som är en stor långsiktig studie där man följer omkring 17000 barn från födsel och framåt under uppväxten. En första studie visade att det fanns stora skillnader i förekomst av autoantikroppar relaterade till typ 1 diabetes mellan två socialt sett helt skilda städer, en gammal arbetarstad och en tjänstemannastad. Det skulle kunna tyda på att det fanns skillnader i stressnivåer för befolkningen i de båda städerna, man kanske skulle kunna benämna det som samhällsstress? Men vad är det som egentligen orsakar sådana skillnader? Vi utvecklade metoden att mäta kortisol i hår och testade den genom att göra en studie på studenter. Den visade att en del stressrelaterade faktorer och händelser som kunde uppfattas som stressfyllda 
faktiskt var kopplade till nivåerna av kortisol i hår. Med denna upptäckt började vi sen undersöka om man kunde använda metoden på barn. Det visade sig att barnens nivåer av kortisol i hår verkar hänga ihop över hela den tidiga barndomen. Spädbarn med höga stressvärden verkade ha fortsatt höga värden under flera år framåt. Barnens nivåer var även kopplade till mammans kortisolnivåer, trots att de är helt olika biologiska varelser. Vi fann också att de barn som tidigt i livet var utsatta för olika typer av psykosocial stress hade en ökad risk att under uppväxten drabbas av nästan alla de vanliga sjukdomarna som barn drabbas av upp till 10 års ålder. Hos barn som tidigt var exponerade för olika former av psykosocial stress kunde vi också mäta högre nivåer av kortisol i hår, ökad nivå av stress gav motsvarande höjning av kortisolnivåer i hår.

De viktigaste fynden i den här avhandlingen stödjer alltså tidigare teorier om att barns fysiologiska stressrespons påverkas av tidig stress och att det påverkar barnets hälsa senare i livet. Den metod vi vidareutvecklat i våra studier som gäller att mäta kortisol i hår verkar vara en mycket användbar metod för att mäta stress i olika psykosociala miljöer, och passar kanske extra bra för forskning om stress på just barn. 


\section{ACKNOWLEDGEMENTS}

This thesis would never have come into existence without the collaboration and support from a large number of people to whom I would like to express my warmest gratitude. In particular I would like to thank:

My supervisors, professor Tomas Faresjö and professor Johnny Ludvigsson. Tomas, for giving me constant inspiration throughout this roller coaster ride, for all the vivid descriptions and explanations, for understanding and guidance through the jungle of problems a doctoral student faces, and for our many interesting discussions. Johnny, for the high expectations, for showing me that one can be a hardworking, highly specialized researcher but still maintain a wise and holistic approach and be a good human being, all at the same time. And also for the e-mail-responses that woke me up at 5 in the morning.

To all 17,000 families that took the time to participate in the ABIS-study, for their effort with filling in the extensive questionnaires and for their permission to cut repeated hair samples so valuable for this thesis.

Elvar Theodorson and Åshild Faresjö who have analysed and developed the hair cortisol samples and guided me in methodological matters.

Co-authors Anneli Frostell-Sepa and Max Hedmark, for wise and stringent discussions in the field of psychology and sociology.

Karl Whalin, the statistician who with remarkable ease explained and discussed statistical matters.

Mats and Ruth Lund for invaluable help with English proofreading.

My friends and colleagues, my manager Åsa, at Ryd Health Care Centre. Without their understanding, in spite of being understaffed, this thesis would not exist. 
My brother Pelle Karlén, for showing me through his illustrations that one can express enormous amounts of care fore children in other ways than writing a thesis.

My extended family, especially my children's grandparents Lena, Håkan, Anne-Marie and Stefan, for their unconditional support through babysitting, despite the many miles that separate us.

And last by not least, my wife Ida and our children Justus and Edith whom I love dearly, for giving me the hours and for being such an inspiration to stop working each and every day. 


\section{REFERENCES}

1. Marmot MG, Wilkinson RG, and Ovid Technologies I. Social determinants of health. Oxford: University Press Oxford; 1999.

2. Ekman R, and Arnetz B. Stress: gen, individ, samhälle. Stockholm: Liber; 2013.

3. Wilkinson RG, and Marmot MG. Social determinants of health: the solid facts. World Health Organization; 2003.

4. Bremberg S. Social differences in ill-health among children and adolescents in Sweden-an overview. Stockholm: Swedish National Institute of Public Health. 2002.

5. Adler NE, Boyce T, Chesney MA, Cohen S, Folkman S, Kahn RL, and Syme SL. Socioeconomic status and health. The challenge of the gradient. Am Psychol. 1994;49(1):15-24.

6. Mazure CM. Life Stressors as Risk Factors in Depression. Clinical Psychology: Science and Practice. 1998;5(3):291-313.

7. Hammen C. Stress and depression. Annu Rev Clin Psychol. 2005;1:293-319.

8. Brotman DJ, Golden SH, and Wittstein IS. The cardiovascular toll of stress. Lancet. 2007;370(9592):1089-100.

9. Rosmond R. Role of stress in the pathogenesis of the metabolic syndrome. Psychoneuroendocrinology. 2005;30(1):1-10.

10. Brunner EJ, Hemingway H, Walker BR, Page M, Clarke P, Juneja M, Shipley MJ, Kumari M, Andrew R, Seckl JR, Papadopoulos A, Checkley S, Rumley A, Lowe GD, Stansfeld SA, and Marmot MG. Adrenocortical, autonomic, and inflammatory causes of the metabolic syndrome: nested case-control study. Circulation. 2002;106(21):2659-65.

11. Kuh D, Hardy R, Langenberg C, Richards M, and Wadsworth ME. Mortality in adults aged 26-54 years related to socioeconomic conditions in childhood and adulthood: post war birth cohort study. BMJ. 2002;325(7372):1076-80.

12. Galobardes B, Lynch JW, and Davey Smith G. Childhood socioeconomic circumstances and cause-specific mortality in adulthood: systematic review and interpretation. Epidemiol Rev. 2004;26:7-21.

13. McLaren L. Socioeconomic status and obesity. Epidemiol Rev. 2007;29:29-48.

14. Tamayo T, Christian H, and Rathmann W. Impact of early psychosocial factors (childhood socioeconomic factors and adversities) on future risk of type 2 diabetes, metabolic disturbances and obesity: a systematic review. BMC Public Health. 2010;10:525.

15. Cohen S, Doyle WJ, and Skoner DP. Psychological stress, cytokine production, and severity of upper respiratory illness. Psychosom Med. 1999;61(2):175-80.

16. Sepa A, Wahlberg J, Vaarala O, Frodi A, and Ludvigsson J. Psychological stress may induce diabetes-related autoimmunity in infancy. Diabetes Care. 2005;28(2):290-5.

17. Cole SW, Kemeny ME, Fahey JL, Zack JA, and Naliboff BD. Psychological risk factors for HIV pathogenesis: mediation by the autonomic nervous system. Biol Psychiatry. 2003;54(12):1444-56.

18. Conger RD, Wallace LE, Sun Y, Simons RL, McLoyd VC, and Brody GH. Economic pressure in African American families: a replication and extension of the family stress model. Dev Psychol. 2002;38(2):179-93. 
19. Danese A, and McEwen BS. Adverse childhood experiences, allostasis, allostatic load, and age-related disease. Physiol Behav. 2012;106(1):29-39.

20. Marmot M. Social determinants of health inequalities. Lancet. 2005;365(9464):1099-104. doi:10.1016/S0140-6736(05)71146-6.

21. Braveman $P$, and Barclay C. Health disparities beginning in childhood: a life-course perspective. Pediatrics. 2009;124 Suppl 3:S163-75.

22. Cohen S, Janicki-Deverts D, Chen E, and Matthews KA. Childhood socioeconomic status and adult health. Ann N Y Acad Sci. 2010;1186:37-55.

23. Evans GW, and Kantrowitz E. Socioeconomic status and health: the potential role of environmental risk exposure. Annu Rev Public Health. 2002;23:303-31.

24. Pampel FC, Krueger PM, and Denney JT. Socioeconomic Disparities in Health Behaviors. Annu Rev Sociol. 2010;36:349-370.

25. Miller G, Chen E, and Cole SW. Health psychology: developing biologically plausible models linking the social world and physical health. Annu Rev Psychol. 2009;60:501-24.

26. Cohen S, Doyle WJ, Skoner DP, Rabin BS, and Gwaltney JM. Social ties and susceptibility to the common cold. JAMA. 1997;277(24):1940-4.

27. Lazarus RS. Psychological stress and the coping process. New York: McGraw-Hill; 1966.

28. Holmes TH, and Rahe RH. The Social Readjustment Rating Scale. J Psychosom Res. 1967;11(2):213-8.

29. Pearlin LI. The sociological study of stress. J Health Soc Behav. 1989;30(3):241-56.

30. Wheaton B. Stress, personal coping resources, and psychiatric symptoms: an investigation of interactive models. J Health Soc Behav. 1983;24(3):208-29.

31. Kaplan S. A model of person-environment compatibility. Environment and Behavior. 1983;15(3):311-332.

32. Rose G. Sick individuals and sick populations. Int J Epidemiol. 1985;14(1):32-8.

33. Susser M, and Susser E. Choosing a future for epidemiology: II. From black box to Chinese boxes and eco-epidemiology. Am J Public Health. 1996;86(5):674-7.

34. Macintyre S, Ellaway A, and Cummins S. Place effects on health: how can we conceptualise, operationalise and measure them? Soc Sci Med. 2002;55(1):125-39.

35. McEwen BS, and Gianaros PJ. Central role of the brain in stress and adaptation: links to socioeconomic status, health, and disease. Ann N Y Acad Sci. 2010;1186:190-222.

36. McEwen BS. Central effects of stress hormones in health and disease: Understanding the protective and damaging effects of stress and stress mediators. Eur J Pharmacol. 2008;583(2-3):174-85.

37. Sluzki CE. Interfaces: toward a new generation of systemic models in family research and practice. Fam Process. 2007;46(2):173-84.

38. Rotter JB. Generalized expectancies for internal versus external control of reinforcement. Psychol Monogr. 1966;80(1):1-28.

39. Chrousos GP, and Gold PW. The concepts of stress and stress system disorders. Overview of physical and behavioral homeostasis. JAMA. 1992;267(9):1244-52.

40. Selye H. Stress and disease. Science. 1955;122(3171):625-31.

41. Harper S, Lynch J, Hsu WL, Everson SA, Hillemeier MM, Raghunathan TE, Salonen JT, and Kaplan GA. Life course socioeconomic conditions and adult psychosocial functioning. Int J Epidemiol. 2002;31(2):395-403. 
42. Marmot MG, Bosma H, Hemingway H, Brunner E, and Stansfeld S. Contribution of job control and other risk factors to social variations in coronary heart disease incidence. Lancet. 1997;350(9073):235-9.

43. Rutter M, Tizard J, Yule W, Graham P, and Whitmore K. Research report: Isle of Wight Studies, 1964-1974. Psychol Med. 1976;6(2):313-32.

44. Repetti RL, Taylor SE, and Seeman TE. Risky families: family social environments and the mental and physical health of offspring. Psychol Bull. 2002;128(2):330-66.

45. Appleyard K, Egeland B, van Dulmen MH, and Sroufe LA. When more is not better: the role of cumulative risk in child behavior outcomes. J Child Psychol Psychiatry. 2005;46(3):235-45.

46. Andrew MK, Mitnitski AB, and Rockwood K. Social vulnerability, frailty and mortality in elderly people. PLoS One. 2008;3(5):e2232.

47. Shi L, Stevens GD, Lebrun LA, Faed P, and Tsai J. Enhancing the measurement of health disparities for vulnerable populations. J Public Health Manag Pract. 2008;14 Suppl:S4552.

48. McEwen BS, and Stellar E. Stress and the individual. Mechanisms leading to disease. Arch Intern Med. 1993;153(18):2093-101.

49. McEwen BS. Protective and damaging effects of stress mediators. N Engl J Med. 1998;338(3):171-9.

50. Seeman T, Epel E, Gruenewald T, Karlamangla A, and McEwen BS. Socio-economic differentials in peripheral biology: cumulative allostatic load. Ann N Y Acad Sci. 2010;1186:223-39.

51. Elder GH. The life course as developmental theory. Child Dev. 1998;69(1):1-12.

52. Kuh D, Ben-Shlomo Y, Lynch J, Hallqvist J, and Power C. Life course epidemiology. J Epidemiol Community Health. 2003;57(10):778-83.

53. Felitti VJ, Anda RF, Nordenberg D, Williamson DF, Spitz AM, Edwards V, Koss MP, and Marks JS. Relationship of childhood abuse and household dysfunction to many of the leading causes of death in adults. The Adverse Childhood Experiences (ACE) Study. Am J Prev Med. 1998;14(4):245-58.

54. Brooks-Gunn J, and Duncan GJ. The effects of poverty on children. Future Child. 1997;7(2):55-71. 55. Bradley RH, and Corwyn RF. Socioeconomic status and child development. Annu Rev Psychol. 2002;53:371-99.

56. Murasko JE. Socioeconomic status, height, and obesity in children. Econ Hum Biol. 2009;7(3):376-86.

57. Spencer NJ, Blackburn CM, and Read JM. Prevalence and social patterning of limiting long-term illness/disability in children and young people under the age of 20 years in 2001: UK census-based cross-sectional study. Child Care Health Dev. 2010;36(4):566-73.

58. Bomela NJ. Social, economic, health and environmental determinants of child nutritional status in three Central Asian Republics. Public Health Nutr. 2009;12(10):18717.

59. Paradise JL, Rockette HE, Colborn DK, Bernard BS, Smith CG, Kurs-Lasky M, and Janosky JE. Otitis media in 2253 Pittsburgh-area infants: prevalence and risk factors during the first two years of life. Pediatrics. 1997;99(3):318-33.

60. Dowd JB, Aiello AE, and Alley DE. Socioeconomic disparities in the seroprevalence of cytomegalovirus infection in the US population: NHANES III. Epidemiol Infect. 2009;137(1):58-65. 
61. Wright RJ, Rodriguez M, and Cohen S. Review of psychosocial stress and asthma: an integrated biopsychosocial approach. Thorax. 1998;53(12):1066-74.

62. Wright RJ, and Subramanian SV. Advancing a multilevel framework for epidemiologic research on asthma disparities. Chest. 2007;132(5 Suppl):757S-769S.

63. Dube SR, Anda RF, Felitti VJ, Chapman DP, Williamson DF, and Giles WH. Childhood abuse, household dysfunction, and the risk of attempted suicide throughout the life span: findings from the Adverse Childhood Experiences Study. JAMA. 2001;286(24):3089-96.

64. Danese A, Pariante CM, Caspi A, Taylor A, and Poulton R. Childhood maltreatment predicts adult inflammation in a life-course study. Proc Natl Acad Sci U S A. 2007;104(4):1319-24. doi:10.1073/pnas.0610362104.

65. Smith GD, Hart C, Blane D, and Hole D. Adverse socioeconomic conditions in childhood and cause specific adult mortality: prospective observational study. BMJ. 1998;316(7145):1631-5.

66. Cohen S, Janicki-Deverts D, Chen E, and Matthews KA. Childhood socioeconomic status and adult health. Ann N Y Acad Sci. 2010;1186:37-55.

67. Barker DJ. The fetal origins of coronary heart disease. Acta Paediatr Suppl. 1997;422:78-82.

68. Tegethoff M, Greene N, Olsen J, Schaffner E, and Meinlschmidt G. Stress during pregnancy and offspring pediatric disease: A National Cohort Study. Environ Health Perspect. 2011;119(11):1647-52.

69. BOWLBY J. The nature of the child's tie to his mother. Int J Psychoanal. 1958;39(5):350-73.

70. McEwen BS. Protective and damaging effects of stress mediators. N Engl J Med. 1998;338(3):171-9.

71. Cacioppo JT, Berntson GG, Malarkey WB, Kiecolt-Glaser JK, Sheridan JF, Poehlmann KM, Burleson MH, Ernst JM, Hawkley LC, and Glaser R. Autonomic, neuroendocrine, and immune responses to psychological stress: the reactivity hypothesis. Ann N Y Acad Sci. 1998;840:664-73.

72. Cohen S, Janicki-Deverts D, and Miller GE. Psychological stress and disease. JAMA. 2007;298(14):1685-7.

73. Karlamangla AS, Singer BH, McEwen BS, Rowe JW, and Seeman TE. Allostatic load as a predictor of functional decline. MacArthur studies of successful aging. J Clin Epidemiol. 2002;55(7):696-710.

74. Segerstrom SC, and Miller GE. Psychological stress and the human immune system: a meta-analytic study of 30 years of inquiry. Psychol Bull. 2004;130(4):601-30.

75. Hotamisligil GS. Inflammation and metabolic disorders. Nature. 2006;444(7121):860-7.

76. Tsigos C, and Chrousos GP. Hypothalamic-pituitary-adrenal axis, neuroendocrine factors and stress. J Psychosom Res. 2002;53(4):865-71.

77. Ludvigsson J. Why diabetes incidence increases--a unifying theory. Ann N Y Acad Sci. 2006;1079:374-82.

78. Sepa A, and Ludvigsson J. Psychological stress and the risk of diabetes-related autoimmunity: a review article. Neuroimmunomodulation. 2006;13(5-6):301-8.

79. Knip M, Kukko M, Kulmala P, Veijola R, Simell O, Akerblom HK, and Ilonen J. Humoral beta-cell autoimmunity in relation to HLA-defined disease susceptibility in preclinical and clinical type 1 diabetes. Am J Med Genet. 2002;115(1):48-54.

80. Barker JM, Barriga KJ, Yu L, Miao D, Erlich HA, Norris JM, Eisenbarth GS, Rewers M, and Diabetes Autoimmunity Study in the Young. Prediction of autoantibody positivity 
and progression to type 1 diabetes: Diabetes Autoimmunity Study in the Young (DAISY). J Clin Endocrinol Metab. 2004;89(8):3896-902.

81. Shirtcliff EA, Coe CL, and Pollak SD. Early childhood stress is associated with elevated antibody levels to herpes simplex virus type 1. Proc Natl Acad Sci U S A. 2009;106(8):2963-7.

82. Cicchetti D, and Rogosch FA. The impact of child maltreatment and psychopathology on neuroendocrine functioning. Dev Psychopathol. 2001;13(4):783-804.

83. Hanson JL, Chung MK, Avants BB, Shirtcliff EA, Gee JC, Davidson RJ, and Pollak SD. Early stress is associated with alterations in the orbitofrontal cortex: a tensor-based morphometry investigation of brain structure and behavioral risk. J Neurosci. 2010;30(22):7466-72.

84. Lopez-Duran NL, Kovacs M, and George CJ. Hypothalamic-pituitary-adrenal axis dysregulation in depressed children and adolescents: a meta-analysis. Psychoneuroendocrinology. 2009;34(9):1272-83.

85. Johnson SB, Riley AW, Granger DA, and Riis J. The science of early life toxic stress for pediatric practice and advocacy. Pediatrics. 2013;131(2):319-27.

86. Irwin LG, Siddiqi A, and Hertzman C. Early child development: a powerful equalizer. Geneva: WHO, Commission on Social Determinants of Health; 2007.

87. Van de Kar LD, and Blair ML. Forebrain pathways mediating stress-induced hormone secretion. Front Neuroendocrinol. 1999;20(1):1-48.

88. Charmandari E, Tsigos C, and Chrousos G. Endocrinology of the stress response. Annu Rev Physiol. 2005;67:259-84. doi:10.1146/annurev.physiol.67.040403.120816.

89. Penza KM, Heim C, and Nemeroff CB. Neurobiological effects of childhood abuse: implications for the pathophysiology of depression and anxiety. Arch Womens Ment Health. 2003;6(1):15-22.

90. Wolkowitz OM, Reus VI, Weingartner H, Thompson K, Breier A, Doran A, Rubinow D, and Pickar D. Cognitive effects of corticosteroids. Am J Psychiatry. 1990;147(10):1297303.

91. Hertsgaard L, Gunnar M, Erickson MF, and Nachmias M. Adrenocortical responses to the strange situation in infants with disorganized/disoriented attachment relationships. Child Dev. 1995;66(4):1100-6.

92. Gröschl M, Rauh M, and Dörr HG. Circadian rhythm of salivary cortisol, 17alphahydroxyprogesterone, and progesterone in healthy children. Clin Chem. 2003;49(10):1688-91.

93. Spangler $G$. The emergence of adrenocortical circadian function in newborns and infants and its relationship to sleep, feeding and maternal adrenocortical activity. Early Hum Dev. 1991;25(3):197-208.

94. Sauvé B, Koren G, Walsh G, Tokmakejian S, and Van Uum SH. Measurement of cortisol in human hair as a biomarker of systemic exposure. Clin Invest Med. 2007;30(5):E183-91.

95. Flinn MV, and England BG. Social economics of childhood glucocorticoid stress response and health. Am J Phys Anthropol. 1997;102(1):33-53.

96. Dickerson SS, and Kemeny ME. Acute stressors and cortisol responses: a theoretical integration and synthesis of laboratory research. Psychol Bull. 2004;130(3):355-91.

97. Filaire E, Duché P, Lac G, and Robert A. Saliva cortisol, physical exercise and training: influences of swimming and handball on cortisol concentrations in women. Eur J Appl Physiol Occup Physiol. 1996;74(3):274-8. 
98. Jonetz-Mentzel L, and Wiedemann G. Establishment of reference ranges for cortisol in neonates, infants, children and adolescents. Eur J Clin Chem Clin Biochem. 1993;31(8):525-9.

99. Lashansky G, Saenger P, Fishman K, Gautier T, Mayes D, Berg G, Di Martino-Nardi J, and Reiter E. Normative data for adrenal steroidogenesis in a healthy pediatric population: age- and sex-related changes after adrenocorticotropin stimulation. J Clin Endocrinol Metab. 1991;73(3):674-86.

100. Elmlinger MW, Kühnel W, and Ranke MB. Reference ranges for serum concentrations of lutropin (LH), follitropin (FSH), estradiol (E2), prolactin, progesterone, sex hormonebinding globulin (SHBG), dehydroepiandrosterone sulfate (DHEAS), cortisol and ferritin in neonates, children and young adults. Clin Chem Lab Med. 2002;40(11):11511160.

101. Gunnar MR, and Donzella B. Social regulation of the cortisol levels in early human development. Psychoneuroendocrinology. 2002;27(1-2):199-220.

102. Kirschbaum C, and Hellhammer D. Response variability of salivary cortisol under psychological stimulation. J Clin Chem Clin Biochem. 1989;27(4):237.

103. Mantagos S, Moustogiannis A, and Vagenakis AG. Diurnal variation of plasma cortisol levels in infancy. J Pediatr Endocrinol Metab. 1998;11(4):549-53.

104. Kiess W, Meidert A, Dressendörfer RA, Schriever K, Kessler U, König A, Schwarz HP, and Strasburger CJ. Salivary cortisol levels throughout childhood and adolescence: relation with age, pubertal stage, and weight. Pediatr Res. 1995;37(4):502-6.

105. Klein J, Karaskov T, Stevens B, Yamada J, and Koren G. Hair cortisol - a potential biological marker for chronic stress. Clin Pharmacol Ther. 2004;75(2):44-9.

106. Yamada J, Stevens B, de Silva N, Gibbins S, Beyene J, Taddio A, Newman C, and Koren G. Hair cortisol as a potential biologic marker of chronic stress in hospitalized neonates. Neonatology. 2007;92(1):42-9.

107. O'Connor TG, Ben-Shlomo Y, Heron J, Golding J, Adams D, and Glover V. Prenatal anxiety predicts individual differences in cortisol in pre-adolescent children. Biol Psychiatry. 2005;58(3):211-7.

108. Yang HZ, Lan J, Meng YJ, Wan XJ, and Han DW. A preliminary study of steroid reproductive hormones in human hair. J Steroid Biochem Mol Biol. 1998;67(5-6):447-50.

109. Wheeler MJ, Zhong YB, Kicman AT, and Coutts SB. The measurement of testosterone in hair. J Endocrinol. 1998;159(1):R5-8.

110. Cirimele V, Kintz P, Dumestre V, Goullé JP, and Ludes B. Identification of ten corticosteroids in human hair by liquid chromatography-ionspray mass spectrometry. Forensic Sci Int. 2000;107(1-3):381-8.

111. Raul JS, Cirimele V, Ludes B, and Kintz P. Detection of physiological concentrations of cortisol and cortisone in human hair. Clin Biochem. 2004;37(12):1105-11.

112. Gaillard Y, Vayssette F, and Pépin G. Compared interest between hair analysis and urinalysis in doping controls. Results for amphetamines, corticosteroids and anabolic steroids in racing cyclists. Forensic Sci Int. 2000;107(1-3):361-79.

113. Stalder T, and Kirschbaum C. Analysis of cortisol in hair - State of the art and future directions. Brain Behav Immun. 2012;26(7):1019-29.

114. Davenport MD, Tiefenbacher S, Lutz CK, Novak MA, and Meyer JS. Analysis of endogenous cortisol concentrations in the hair of rhesus macaques. Gen Comp Endocrinol. 2006;147(3):255-61. 
115. Davenport MD, Lutz CK, Tiefenbacher S, Novak MA, and Meyer JS. A rhesus monkey model of self-injury: effects of relocation stress on behavior and neuroendocrine function. Biol Psychiatry. 2008;63(10):990-6.

116. Sauvé B, Koren G, Walsh G, Tokmakejian S, and Van Uum SH. Measurement of cortisol in human hair as a biomarker of systemic exposure. Clin Invest Med. 2007;30(5):183-91.

117. Kalra S, Einarson A, Karaskov T, Van Uum S, and Koren G. The relationship between stress and hair cortisol in healthy pregnant women. Clin Invest Med. 2007;30(2):103-7.

118. Van Uum SH, Sauvé B, Fraser LA, Morley-Forster P, Paul TL, and Koren G. Elevated content of cortisol in hair of patients with severe chronic pain: a novel biomarker for stress. Stress. 2008;11(6):483-8.

119. Kirschbaum C, Tietze A, Skoluda N, and Dettenborn L. Hair as a retrospective calendar of cortisol production-Increased cortisol incorporation into hair in the third trimester of pregnancy. Psychoneuroendocrinology. 2009;34(1):32-7.

120. Manenschijn L, van Kruysbergen RG, de Jong FH, Koper JW, and van Rossum EF. Shift work at young age is associated with elevated long-term cortisol levels and body mass index. J Clin Endocrinol Metab. 2011;96(11):1862-5.

121. Henley P, and Koren G. Preschoolers' hair cortisol levels are linked to parental income. Ther Drug Monit. 2014;36(2):133-5.

122. Karlen J, Ludvidsson J, Frostell A, Theodorsson E, and Faresjo T. Cortisol in hair measured in young adults - a biomarker of major life stressors? BMC Clin Pathol. 2011;11(1):12.

123. Dettenborn L, Tietze A, Bruckner F, and Kirschbaum C. Higher cortisol content in hair among long-term unemployed individuals compared to controls. Psychoneuroendocrinology. 2010;35(9):1404-9.

124. Stalder T, Steudte S, Alexander N, Miller R, Gao W, Dettenborn L, and Kirschbaum C. Cortisol in hair, body mass index and stress-related measures. Biol Psychol. 2012;90(3):218-23.

125. Faresjö A, Theodorsson E, Chatziarzenis M, Sapouna V, Claesson HP, Koppner J, and Faresjö T. Higher Perceived Stress but Lower Cortisol Levels Found among Young Greek Adults Living in a Stressful Social Environment in Comparison with Swedish Young Adults. PLoS One. 2013;8(9):e73828.

126. Chan J, Sauvé B, Tokmakejian S, Koren G, and Van Uum S. Measurement of cortisol and testosterone in hair of obese and non-obese human subjects. Exp Clin Endocrinol Diabetes. 2014;122(6):356-62. doi:10.1055/s-0034-1374609.

127. Luo H, Hu X, Liu X, Ma X, Guo W, Qiu C, Wang Y, Wang Q, Zhang X, Zhang W, Hannum G, Zhang K, Liu X, and Li T. Hair cortisol level as a biomarker for altered hypothalamic-pituitary-adrenal activity in female adolescents with posttraumatic stress disorder after the 2008 Wenchuan earthquake. Biol Psychiatry. 2012;72(1):65-9.

128. Steudte S, Kolassa IT, Stalder T, Pfeiffer A, Kirschbaum C, and Elbert T. Increased cortisol concentrations in hair of severely traumatized Ugandan individuals with PTSD. Psychoneuroendocrinology. 2011;36(8):1193-200.

129. Manenschijn L, Spijker AT, Koper JW, Jetten AM, Giltay EJ, Haffmans J, Hoencamp E, and van Rossum EF. Long-term cortisol in bipolar disorder: associations with age of onset and psychiatric co-morbidity. Psychoneuroendocrinology. 2012;37(12):1960-8.

130. Veldhorst MA, Noppe G, Jongejan MH, Kok CB, Mekic S, Koper JW, van Rossum EF, and van den Akker EL. Increased scalp hair cortisol concentrations in obese children. $J$ Clin Endocrinol Metab. 2014;99(1):285-90. 
131. Wester VL, Staufenbiel SM, Veldhorst MA, Visser JA, Manenschijn L, Koper JW, Klessens-Godfroy FJ, van den Akker EL, and van Rossum EF. Long-term cortisol levels measured in scalp hair of obese patients. Obesity (Silver Spring). 2014;22(9):1956-8.

132. Manenschijn L, Koper JW, Lamberts SW, and van Rossum EF. Evaluation of a method to measure long term cortisol levels. Steroids. 2011;76(10-11):1032-6.

133. Pereg D, Chan J, Russell E, Berlin T, Mosseri M, Seabrook JA, Koren G, and Van Uum S. Cortisol and testosterone in hair as biological markers of systolic heart failure. Psychoneuroendocrinology. 2013;38(12):2875-82.

134. Pereg D, Gow R, Mosseri M, Lishner M, Rieder M, Van Uum S, and Koren G. Hair cortisol and the risk for acute myocardial infarction in adult men. Stress. 2010;14(1):7381.

135. Statistics Sweden. Statistisk årsbok 1999 (The statistic year book 1999). Stockholm: Nordstedts tryckeri AB; 1999.

136. Sepa A. The Stress Hypothesis: Implications for the induction of diabetes-related autoimmunity in children? [dissertation] Linköping: Linköping University; 2004.

137. Faresjö T, Söderquist J, Ludvigsson J, Grodzinsky E, and Nilsson H. Twin cities with big social differences when it comes to public health. A sociomedical "experiment" introduced in Norrkoping and Linkoping. Lakartidningen. 2007;104(23):1788-90.

138. Faresjö T, and Rahmqvist M. Educational level is a crucial factor for good perceived health in the local community. Scand J Public Health. 2010;38(6):605-10.

139. Wennerholm C, Grip B, Johansson A, Nilsson H, Honkasalo ML, and Faresjö T. Cardiovascular disease occurrence in two close but different social environments. Int J Health Geogr. 2011;10:5.

140. Grodzinsky E, Hallert C, Faresjö T, Bergfors E, and Faresjö AO. Could gastrointestinal disorders differ in two close but divergent social environments? Int J Health Geogr. 2012;11:5.

141. Morelius E, Nelson N, and Theodorsson E. Salivary cortisol and administration of concentrated oral glucose in newborn infants: improved detection limit and smaller sample volumes without glucose interference. Scand J Clin Lab Invest. 2004;64(2):113-8.

142. Gustafsson Stolt U. Aspects in bioethics: Theory and practice in a preventive screening for type 1 diabetes. [dissertation] Linköping: Linköping University; 2003.

143. Norman G. Likert scales, levels of measurement and the "laws" of statistics. Adv Health Sci Educ Theory Pract. 2010;15(5):625-32.

144. Wahlberg J, Fredriksson J, Nikolic E, Vaarala O, Ludvigsson J, and ABIS-Study Group. Environmental factors related to the induction of beta-cell autoantibodies in 1-yr-old healthy children. Pediatr Diabetes. 2005;6(4):199-205.

145. Törn C, Mueller PW, Schlosser M, Bonifacio E, Bingley PJ, and Participating Laboratories. Diabetes Antibody Standardization Program: evaluation of assays for autoantibodies to glutamic acid decarboxylase and islet antigen-2. Diabetologia. 2008;51(5):846-52.

146. Cohen S, Kamarck T, and Mermelstein R. A global measure of perceived stress. J Health Soc Behav. 1983;24(4):385-96.

147. Vaarala O, Hyöty H, and Akerblom HK. Environmental factors in the aetiology of childhood diabetes. Diabetes Nutr Metab. 1999;12(2):75-85. 
148. McKinney PA, Okasha M, Parslow RC, Law GR, Gurney KA, Williams R, and Bodansky HJ. Early social mixing and childhood Type 1 diabetes mellitus: a case-control study in Yorkshire, UK. Diabet Med. 2000;17(3):236-42.

149. Bonifacio E, Bingley PJ, Shattock M, Dean BM, Dunger D, Gale EA, and Bottazzo GF. Quantification of islet-cell antibodies and prediction of insulin-dependent diabetes. Lancet. 1990;335(8682):147-9.

150. Komulainen J, Kulmala P, Savola K, Lounamaa R, Ilonen J, Reijonen H, Knip M, and Akerblom HK. Clinical, autoimmune, and genetic characteristics of very young children with type 1 diabetes. Childhood Diabetes in Finland (DiMe) Study Group. Diabetes Care. 1999;22(12):1950-5.

151. Borchers AT, Uibo R, and Gershwin ME. The geoepidemiology of type 1 diabetes. Autoimmun Rev. 2010;9(5):A355-65.

152. Hjern A, Haglund B, Rasmussen F, and Rosén M. Socio-economic differences in daycare arrangements and use of medical care and antibiotics in Swedish preschool children. Acta Paediatr. 2000;89(10):1250-6.

153. Cohen S, Line S, Manuck SB, Rabin BS, Heise ER, and Kaplan JR. Chronic social stress, social status, and susceptibility to upper respiratory infections in nonhuman primates. Psychosom Med. 1997;59(3):213-21.

154. Cohen S, Tyrrell DA, and Smith AP. Psychological stress and susceptibility to the common cold. N Engl J Med. 1991;325(9):606-12.

155. Kanner AD, Coyne JC, Schaefer C, and Lazarus RS. Comparison of two modes of stress measurement: daily hassles and uplifts versus major life events. J Behav Med. 1981;4(1):1-39.

156. Watamura SE, Sebanc AM, and Gunnar MR. Rising cortisol at childcare: relations with nap, rest, and temperament. Dev Psychobiol. 2002;40(1):33-42.

157. Vaghri Z, Guhn M, Weinberg J, Grunau RE, Yu W, and Hertzman C. Hair cortisol reflects socio-economic factors and hair zinc in preschoolers. Psychoneuroendocrinology. 2012;38(3):331-40.

158. Federenko IS, Nagamine M, Hellhammer DH, Wadhwa PD, and Wüst S. The heritability of hypothalamus pituitary adrenal axis responses to psychosocial stress is context dependent. J Clin Endocrinol Metab. 2004;89(12):6244-50.

159. Wüst S, Federenko IS, van Rossum EF, Koper JW, Kumsta R, Entringer S, and Hellhammer DH. A psychobiological perspective on genetic determinants of hypothalamus-pituitary-adrenal axis activity. Ann N Y Acad Sci. 2004;1032:52-62.

160. Murgatroyd C, and Spengler D. Epigenetics of early child development. Front Psychiatry. 2011;2:16.

161. Hofer MA. Psychobiological roots of early attachment. Curr Dir Psychol Sci. 2006;15(2):84-88.

162. Madigan S, Bakermans-Kranenburg MJ, Van Ijzendoorn MH, Moran G, Pederson DR, and Benoit D. Unresolved states of mind, anomalous parental behavior, and disorganized attachment: a review and meta-analysis of a transmission gap. Attach Hum Dev. 2006;8(2):89-111.

163. van IJzendoorn $\mathrm{MH}$. Adult attachment representations, parental responsiveness, and infant attachment: a meta-analysis on the predictive validity of the Adult Attachment Interview. Psychol Bull. 1995;117(3):387-403.

164. Meaney MJ, Szyf M, and Seckl JR. Epigenetic mechanisms of perinatal programming of hypothalamic-pituitary-adrenal function and health. Trends Mol Med. 2007;13(7):269-77. 
165. Meaney MJ. Maternal care, gene expression, and the transmission of individual differences in stress reactivity across generations. Annu Rev Neurosci. 2001;24:1161-92.

166. Fries E, Hesse J, Hellhammer J, and Hellhammer DH. A new view on hypocortisolism. Psychoneuroendocrinology. 2005;30(10):1010-6.

167. Cohen S, Doyle WJ, and Baum A. Socioeconomic status is associated with stress hormones. Psychosom Med. 2006;68(3):414-20.

168. Wrosch C, Bauer I, Miller GE, and Lupien S. Regret intensity, diurnal cortisol secretion, and physical health in older individuals: evidence for directional effects and protective factors. Psychol Aging. 2007;22(2):319-30.

169. Söndergaard HP, Kushnir MM, Aronsson B, Sandstedt P, and Bergquist J. Patterns of endogenous steroids in apathetic refugee children are compatible with long-term stress. BMC Res Notes. 2012;5:186.

170. Akerstedt T, Knutsson A, Alfredsson L, and Theorell T. Shift work and cardiovascular disease. Scand J Work Environ Health. 1984;10(6):409-14.

171. Pollitt RA, Rose KM, and Kaufman JS. Evaluating the evidence for models of life course socioeconomic factors and cardiovascular outcomes: a systematic review. BMC Public Health. 2005;5:7.

172. Stalder T, Steudte S, Miller R, Skoluda N, Dettenborn L, and Kirschbaum C. Intraindividual stability of hair cortisol concentrations. Psychoneuroendocrinology. 2011;37(5):602-10.

173. Qi X, Zhang J, Liu Y, Ji S, Chen Z, Sluiter JK, and Deng H. Relationship between effortreward imbalance and hair cortisol concentration in female kindergarten teachers. $J$ Psychosom Res. 2014;76(4):329-32.

174. Rothman KJ, Greenland S, and Lash TL. Modern epidemiology. Philadelphia: Lippincott Williams \& Wilkins; 2008.

175. Rosengren A, Hawken S, Ounpuu S, Sliwa K, Zubaid M, Almahmeed WA, Blackett KN, Sitthi-amorn C, Sato H, Yusuf S, and INTERHEART investigators. Association of psychosocial risk factors with risk of acute myocardial infarction in 11119 cases and 13648 controls from 52 countries (the INTERHEART study): case-control study. Lancet. 2004;364(9438):953-62.

176. Kurland LT, and Molgaard CA. The patient record in epidemiology. Scientific American. 1981;245(4):54.

177. Dettenborn L, Tietze A, Kirschbaum C, and Stalder T. The assessment of cortisol in human hair - associations with sociodemographic variables and potential confounders. Stress. 2012;15(6):578-88.

178. Loussouarn G, El Rawadi C, and Genain G. Diversity of hair growth profiles. Int J Dermatol. 2005;44 Suppl 1:6-9.

179. Binder EB, and Holsboer F. Low cortisol and risk and resilience to stress-related psychiatric disorders. Biol Psychiatry. 2012;71(4):282-3.

180. Hammerfald K, Eberle C, Grau M, Kinsperger A, Zimmermann A, Ehlert U, and Gaab J. Persistent effects of cognitive-behavioral stress management on cortisol responses to acute stress in healthy subjects--a randomized controlled trial. Psychoneuroendocrinology. 2006;31(3):333-9.

181. Ito N, Ito T, Kromminga A, Bettermann A, Takigawa M, Kees F, Straub RH, and Paus R. Human hair follicles display a functional equivalent of the hypothalamic-pituitaryadrenal axis and synthesize cortisol. FASEB J. 2005;19(10):1332-4. 
182. Sharpley CF, McFarlane JR, and Slominski A. Stress-linked cortisol concentrations in hair: what we know and what we need to know. Rev Neurosci. 2012;23(1):111-21.

183. Thomson S, Koren G, Van Steen V, Rieder M, and Van Uum SH. Testosterone concentrations in hair of hypogonadal men with and without testosterone replacement therapy. Ther Drug Monit. 2009;31(6):779-82.

184. Albar WF, Russell EW, Koren G, Rieder MJ, and van Umm SH. Human hair cortisol analysis: comparison of the internationally-reported ELISA methods. Clin Invest Med. 2013;36(6):312-6.

185. Pragst F, and Balikova MA. State of the art in hair analysis for detection of drug and alcohol abuse. Clin Chim Acta. 2006;370(1-2):17-49.

186. Mueller BR, and Bale TL. Sex-specific programming of offspring emotionality after stress early in pregnancy. J Neurosci. 2008;28(36):9055-65.

187. Rodgers AB, Morgan CP, Bronson SL, Revello S, and Bale TL. Paternal stress exposure alters sperm microRNA content and reprograms offspring HPA stress axis regulation. $J$ Neurosci. 2013;33(21):9003-12.

188. Pembrey M, Saffery R, Bygren LO, and Network in Epigenetic Epidemiology. Human transgenerational responses to early-life experience: potential impact on development, health and biomedical research. J Med Genet. 2014;51(9):563-572.

189. Slopen N, McLaughlin KA, and Shonkoff JP. Interventions to improve cortisol regulation in children: a systematic review. Pediatrics. 2014;133(2):312-26. 



\section{Papers}

The articles associated with this thesis have been removed for copyright reasons. For more details about these see:

http://urn.kb.se/resolve?urn=urn:nbn:se:liu:diva-111096 